Universidade de São Paulo

Instituto de Física

\title{
Estudo da distribuição de momento de elétrons ligados por correlação ângulo-energia da radiação de aniquilação elétron-pósitron
}

\author{
Leandro Mariano \\ Orientador: Prof. Dr. Otaviano A. M. Helene
}

Dissertação de mestrado apresentada ao Instituto de Física para a obtenção do título de Mestre em Ciências.

Comissão Examinadora:

Prof. Dr. José Roberto Brandão de Oliveira (IFUSP)

Profa. Dra. Maria Cristina Andreolli Lopes (UFJF)

Prof. Dr. Otaviano Augusto Marcondes Helene (IFUSP)

São Paulo

2010 
Autorizo a reprodução e divulgação total e parcial deste trabalho, por qualquer meio convencional ou eletrônico, desde que citada a fonte.

\section{FICHA CATALOGRÁFICA}

Preparada pelo Serviço de Biblioteca e Informação do Instituto de Física da Universidade de São Paulo

Mariano, Leandro

Estudo da distribuição de momento de elétrons ligados por correlação ângulo-energia da radiação de aniquilação elétron-pósitron. São Paulo, 2010.

Dissertação (Mestrado) - Universidade de São Paulo. Instituto de Física - Depto. de Física Experimental.

Orientador: Prof. Dr. Otaviano Augusto Marcondes Helene

Área de Concentração: Física

Unitermos: 1. Alargamento Doppler; 2. Aniquilação de pósitrons; 3. Momento de elétrons; 4. Espectroscopia de raio gama. 
Aos meus pais, pelo apoio incondicional ao longo dos anos e à Tatiane, por ter me oferecido uma mão enquanto eu estava caído. 


\section{Agradecimentos}

Gostaria de agradecer aos meus pais, Nilson e Maria, por terem praticamente dedicado uma vida ao estudo e bem estar dos seus filhos.

Ao professor Otaviano Helene, por me orientar e ajudar em questões não somente relativas à física, mas também por estar sempre disposto a discutir qualquer questão sobre ciências em geral ou política. Agradeço seu apoio e paciência ao longo de todos esses anos.

À minha amiga Tatiane que me ofereceu a mão no momento em que eu mais precisava de ajuda. Pelos chás da tarde e por transmitir essa alegria para todos à sua volta. E também por me incentivar tanto pra "acabar logo esta dissertação".

Ao Zwinglio, que me ajudou muito quando estava no Brasil e ainda me ajuda indiretamente. Por ter me ensinado os princípios de análise de dados, programação em Matlab, por ter me apresentado ao professor Otaviano e por tantas outras coisas que eu nem me lembro.

Ao Lelas, com quem divido sala desde 2006, pela ajuda em inúmeras e ótimas conversas sobre física, ou não.

À Nathy, pelas incontáveis caronas, pelos desabafos e por me ensinar a não me importar com lugares que não valem a pena.

À Melina, pelas conversas, apoio e pelas cervejas até boa parte da madrugada pra ajudar a suportar aquele hospício que é o Crusp.

À Alice, que estava no início desta caminhada e de quem eu só guardo as boas memórias.

Aos meus amigos Shock e Aline por me acolherem no Crusp neste período final do projeto. Sem esta ajuda, não teria conseguido.

Aos meus amigos Viktor, Felis, Felipo, Igino, Josi, Cris, Tiago, Renata, Diogo e Jairo pela companhia, pelos cafés, pelas risadas e pelas sugestões no projeto.

Às pessoas que compartilharam dessa caminhada, mas não estão mais no Instituto. Em especial César Guimarães e ao Washington que dividiram sala comigo, pela inestimável ajuda em diversas questões. Aos cubanos César Trápaga e Katherin pelas inúmeras discussões sobre como era a vida em seu 
país.

À todos os funcionários do LAL, em especial ao Cacá e ao Edu, sempre dispostos a ajudar os alunos. A Juliana, por nunca negar um favor e ao Korogui por toda inestimável ajuda com questões de computação e para o qual devo incontáveis cigarros. Ao pessoal da oficina mecânica, especialmente ao Betão e ao Wilson, pela ajuda no desenvolvimento das peças do filtro angular.

À professora Ana Regina Blak, com quem eu aprendi que o bom humor, o respeito e os bons pensamentos estão acima de qualquer coisa. Aos professores Vito Vanin, Philippe Gouffon e Ivone Albuquerque pelas discussões e ajuda.

À Eduardo Nascimento, com o qual convivi pouco pessoalmente, mas cuja tese foi inestimável companheira.

Ao Maurício Morales por ajudar na preparação da amostra radiotiva no IPEN.

Às agências de fomento CNPQ e FAPESP. 


\section{Resumo}

Neste trabalho foi medido o alargamento Doppler de uma aniquilação elétron pósitron com o uso de um filtro angular. O Filtro angular reduz, substancialmente, a detecção de fótons provenientes de aniquilações de elétrons com baixo momento, enfatizando, desta forma, a contribuição de aniquilações com elétrons fortemente ligados. Foram medidos os espectros de coincidência para os ângulos de corte de $0,28^{\circ}, 0,42^{\circ}$ e $1.2^{\circ}$.

Os resultados obtidos mostram que, conforme se aumenta o ângulo de corte, há uma redução das aniquilações com elétrons de valência em proporção muito maior do que para elétrons fortemente ligados.

Foi determinada a transmissibilidade do filtro em função do ângulo entre as direções de emissão dos gamas, levando em conta todos os elementos do arranjo experimental para cada ângulo crítico, assim como a distribuição espacial da atividade da fonte radioativa.

Um modelo simples foi utilizado para estimar teoricamente a dependência da dispersão da energia em função do ângulo de corte. Este modelo permitiu calcular o alargamento Doppler da radiação de aniquilação elétron pósitron. Os resultados obtidos mostram um bom acordo com os dados experimentais.

Geralmente, estudos de aniquilação de pósitrons com elétrons fortemente ligados dependem de uma modelagem detalhada do espectro de coincidência, ou da medida dos fótons provenientes da aniquilação em coincidência com elétrons Auger. O filtro angular, desenvolvido neste trabalho se coloca como uma boa alternativa a estes métodos. 


\section{Abstract}

This work reports the measurement of the Doppler broadening of the electron-positron annihilation radiation using an angular filter. The angular filter substantially reduces the number of detected gamma-rays from positron annihilation with low momentum electrons, therefore emphasizing the contribution of bound electron. Four coincidence measurements of the emitted gamma-rays were done with arrangements corresponding to critical angles of $0.28^{\circ}, 0.42^{\circ}, 1.2^{\circ}$.

The obtained results show that the relative intensity of annihilation with valence electrons decreases as the critical angle increases.

The filter transmissibility as a function of the angle between the two gamma-rays emission directions was determined taking into account all the elements of the experimental arrangement for every critical angle as well as the spatial distribution of the source activity.

A simple model was used to theoretically estimate the dependence of the energy dispersion on the critical angle. The model allows us to calculate the Doppler broadening of the electron-positron annihilation radiation, and the obtained results show good agreement with the experimental data.

Usually, the study of positrons annihilation with inner electrons requires good detectors' energy resolution and depends on either sophisticated modeling and statistical analysis of the coincidence spectra or the measurement of the annihilation gamma-rays in coincidence with Auger electrons. The use of the angular filter developed in this work is a good alternative to those procedures. 


\section{Sumário}

Agradecimentos iv

Resumo vi vi vo ving

Abstract vii

Sumário viii

$\begin{array}{lll}\mathbf{1} & \text { Introdução } & \mathbf{1}\end{array}$

1.1 Experimentos de aniquilação de pósitrons: Visão geral . . . . 1

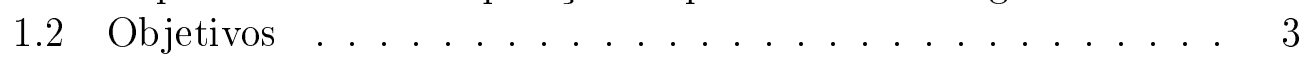

1.3 Teoria do Processo de aniquilação . . . . . . . . . . . . . 4

1.3.1 Cinemática ....................... 5

1.4 Espectro de coincidência . . . . . . . . . . . . . . . . . . . 8

1.5 Filtro angular . . . . . . . . . . . . . . . . . . . 12

$1.6 \quad$ Funções densidade de probabilidade de $p_{/ /}$e $p_{\perp} \ldots \ldots . . . .12$

$\begin{array}{llr}2 & \text { Experimental } & 16\end{array}$

2.1 Amostra . . . . . . . . . . . . . . . . 16

$2.1 .1 \quad$ Fontes de ${ }^{22} \mathrm{Na} \ldots \ldots \ldots \ldots \ldots$

2.2 Filtro Angular . . . . . . . . . . . . . . . . . . 18

2.2.1 Avaliação da transmissibilidade do filtro angular . . . . 20

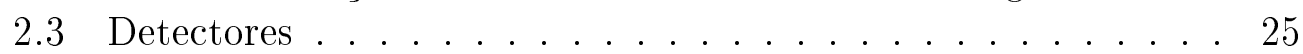

2.4 Sistema Multidetector . . . . . . . . . . . . . 27

2.5 Medidas realizadas . . . . . . . . . . . . . . 28

3 Dados obtidos e Análise $\quad 29$

3.1 Resultados obtidos . . . . . . . . . . . . . . . . . . . 29

3.2 Modelagem . . . . . . . . . . . . . . . . . 34

3.2 .1 Comparação com os valores medidos . . . . . . . . 39

3.3 Ajuste . . . . . . . . . . . . . . . . . . . . 41 
SUMÁRIO - ix

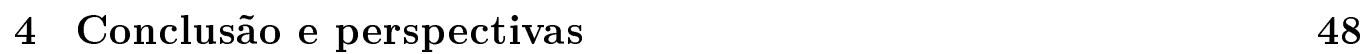

\begin{tabular}{ll}
\hline Referências Bibliográficas & 50
\end{tabular} 


\section{Capítulo 1}

\section{Introdução}

Neste capítulo será apresentada uma visão geral dos experimentos envolvendo aniquilação de pósitrons. Serão mostradas as grandezas que podem ser obtidas com este tipo de experimento, as principais técnicas experimentais utilizadas, um resumo teórico do processo de aniquilação, além dos objetivos do experimento descrito neste trabalho.

\subsection{Experimentos de aniquilação de pósitrons: Visão geral}

A aniquilação de pósitrons é um importante recurso para estudar a estrutura eletrônica dos materiais. Nesta técnica, pósitrons penetram no material a ser estudado e se aniquilam com elétrons em seu interior gerando radiação gama. Através da medida dessa radiação é possível determinar diversas propriedades do elétron que participou da aniquilação e assim obter informações do material estudado. Os parâmetros que podem ser medidos em uma aniquilação elétron-pósitron são a energia de um ou ambos os gamas emitidos, o ângulo entre esses gamas, a taxa de aniquilação e o tempo de vida do pósitron no material.

Os primeiros trabalhos usando pósitrons para analisar a estrutura eletrônica dos materiais são da década de 40 e 50 [1, 2]. Estes trabalhos utilizavamse de detectores cintiladores para avaliar o desvio de colinearidade dos fótons 
emitidos na aniquilação, técnica que posteriormente ficou conhecida como Correlação Angular da Radiação de Aniquilação.

O advento dá técnica de medida do Alargamento Doppler, principalmente após inclusão de um segundo detector semicondutor no arranjo experimental [3], permitiu o estudo da parte do espectro de coincidência devido a aniquilação com altos momentos. Estas aniquilações são dominadas por elétrons fortemente ligados, e, portanto, permitem obter o elemento químico do material na região da aniquilação.

Recentemente, no laboratório do Acelerador Linear no Instituto de Física da USP, foi desenvolvida uma técnica para o ajuste de funções modelos diretamente nos espectros de coincidência dos fótons gerados na aniquilação [4, 5]. Essa técnica permitiu um estudo detalhado da porção do espectro de coincidência devido a aniquilações com elétrons fortemente ligados. O presente projeto dá continuidade a esses trabalhos e é uma alternativa para medida da radiação de aniquilação proveniente de elétrons fortemente ligados.

No referencial do centro de massa, a aniquilação de um elétron livre com um pósitron dá origem a dois gamas emitidos a $180^{\circ}$ cada um com energia igual a energia de repouso do elétron. Porém, no referencial do laboratório esses gamas sofrem deslocamento Doppler e o ângulo entre eles é ligeiramente diferente de $180^{\circ}$.

Os principais estudos em aniquilação de pósitrons se baseiam em duas características básicas deste processo. A sensibilidade dos parâmetros da aniquilação em relação à densidade local de elétrons e em relação a função densidade de probabilidade $(f d p)$ do momento linear dos elétrons no material.

A sensibilidade destes parâmetros à densidade local de elétrons é, geralmente, utilizada para o estudo de defeitos (vacâncias, por exemplo) em redes cristalinas. A principal técnica utilizada para esse fim é a Espectroscopia de Vida Média.

Quando um pósitron penetra em um material livre de defeitos sua função de onda vai rapidamente para o estado fundamental, não localizado (processo de termalização). Neste caso, como não há outros pósitrons no material, a energia cinética do pósitron é da ordem de $k_{B} T$ (sendo que $k_{B}$ é a constante 
de Boltzmann e T é a temperatura do material) e, portanto, bem menor que a energia dos elétrons.

Caso haja um defeito na rede cristalina a função de onda do pósitron é localizada na região do defeito (armadilhamento) e a aniquilação se dá com em elétron da vizinhança deste defeito. Como a densidade local de elétrons na região do defeito é diferente da densidade em uma região livre de defeitos, a vida média do pósitron tem seu valor alterado. A sensibilidade dessa técnica inicia-se por volta de uma vacância por $10^{7}$ átomos [6].

A sensibilidade dos parâmetros da aniquilação em função da $f d p$ do momento dos elétrons é explicada pela cinemática do processo de aniquilação. Como será mostrado na seção 1.3.1, a mudança de referencial entre o centro de massa e o laboratório, faz com que a energia dos gamas gerados na aniquilação esteja relacionada com a componente do momento dos elétrons paralela à direção de aniquilação e o ângulo entre eles esteja relacionado com a componente do momento perpendicular à essa direção. Além disso, através da energia total dos gamas, é possível obter a energia de ligação do elétron aniquilado e, assim, caracterizar o elemento químico do material envolvido na aniquilação.

Os fenômenos decorrentes da mudança de referencial entre o centro de massa e laboratório, dão origem a duas técnicas experimentais importantes: a Medida do Alargamento Doppler e a Medida da Correlação Angular de Radiação de Aniquilação (ACAR), que permitem obter, respectivamente, a função densidade de probabilidade das componentes paralela e perpendicular dos momentos dos elétrons.

\subsection{Objetivos}

O objetivo deste experimento é medir a energia dos gamas emitidos numa aniquilação elétron-pósitron e assim conhecer a componente do momento dos elétrons longitudinal à direção de aniquilação, porém, com o uso de um filtro angular desenvolvido neste projeto. Este filtro permite estimar, também, a componente do momento perpendicular à direção de emissão fazendo, assim, um estudo mais detalhado do processo de aniquilação. 
Uma região de particular interesse no espectro de coincidência é a formada por aniquilações com elétrons fortemente ligados. Nesse caso, as aniquilações com elétrons de condução, que são da ordem de $90 \%$ do total de eventos, funcionam como fundo para as medidas de interesse. Algumas soluções podem ser utilizadas para contornar esse problema. A primeira consiste em obter uma grande quantidade de eventos [7], o que implica no uso de fontes radioativas muito intensas ou em tempo de medida muito grande. A segunda consiste na modelagem do espectro de coincidência [4, 5], o que requer uma análise estatística detalhada. Uma terceira possibilidade é medir os fótons da aniquilação em coincidência com elétrons Auger [8], o que implica no uso de amostras extremamente finas. O filtro angular desenvolvido é uma alternativa para reduzir significativamente as aniquilações com elétrons de condução, facilitando a observação de aniquilações com elétrons fortemente ligados.

Para entender o funcionamento deste filtro é necessário estudar a cinemática do processo de aniquilação. Na seção 1.3.1 são deduzidas as relações entre a energia e o ângulo dos fótons emitidos na aniquilação em função do momento do par elétron-pósitron.

\subsection{Teoria do Processo de aniquilação}

A descrição teórica conveniente do processo de aniquilação pode ser feita pela Eletrodinâmica Quântica [9]. A taxa de aniquilação, as funções densidade de probabilidade do momento do par e sua energia podem ser obtidas, desde que conhecidas as funções de onda do elétron e do pósitron aniquilado. Essas funções de onda podem ser obtidas por modelos em Física do estado sólido. Porém, as principais relações utilizadas nesse projeto podem ser obtidas por um modelo semiclássico da cinemática do processo de aniquilação. A descrição desse modelo é simples e ajuda a compreender os objetivos do experimento apresentado neste trabalho. 


\subsubsection{Cinemática}

A descrição da cinemática do processo de aniquilação, no caso onde o par elétron-pósitron está em repouso e em um estado não ligado é trivial. Como o momento linear inicial é zero, quando dois gamas são emitidos, eles são colineares e cada fóton tem energia igual a energia de repouso do elétron $\left(E_{0}=511 \mathrm{keV}\right)$. No caso do par elétron pósitron estar em movimento no referencial do laboratório, pode-se resolver o problema no referencial do centro de massa, onde os gamas continuam sendo colineares, e depois voltar para o referencial do laboratório.

No referencial do centro de massa, os ângulos entre os gamas emitidos $\left(\gamma_{1}\right.$ e $\left.\gamma_{2}\right)$ e a direção do momento do par elétron-pósitron $\left(P_{c m}\right)$ são $\theta_{1}$ e $\theta_{2}$. O momento do par elétron-pósitron pode ser decomposto nas componentes paralela $\left(p_{/ /}\right)$e perpendicular $\left(p_{\perp}\right)$ à direção de aniquilação.

$$
\begin{aligned}
& p_{\perp}=p \operatorname{sen} \theta \\
& p_{/ /}=p \cos \theta
\end{aligned}
$$

sendo que $\theta=\theta_{1}^{\prime}$.

A figura 1.1 ajuda a entender a cinemática do processo.

No referencial do laboratório, a componente perpendicular do momento do centro de massa $\left(p_{\perp}\right)$ é responsável por um pequeno ângulo $(\alpha)$ entre a direção de emissão dos gamas $\left(\theta_{1}^{\prime}\right.$ e $\left.\theta_{2}^{\prime}\right)$ e a componente paralela deste momento $\left(p_{/ /}\right)$está relacionada a diferença de energia entre os gamas. As energias dos fótons no referencial do laboratório e o ângulo entre eles podem ser obtidos através da relações do deslocamento Doppler relativístico entre o referencial do laboratório e do centro de massa.

Seja um fóton de frequência $\omega$, cuja direção de propagação faz um ângulo $\theta$ com a direção do momento do par elétron-pósitron, no referencial do centro de massa. No referencial do laboratório, este fóton terá uma frequência $\omega^{\prime}$ e uma direção de propagação $\theta^{\prime}$ dadas por [10]: 


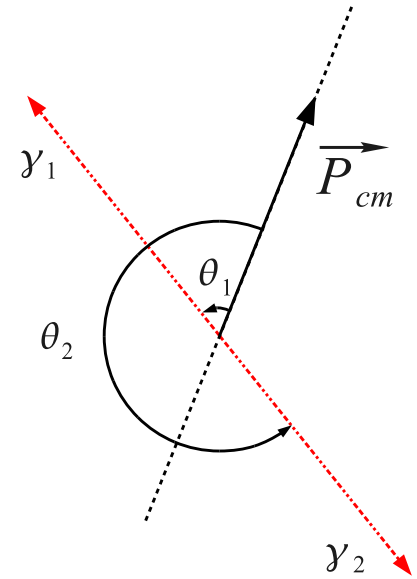

(a) centro de massa

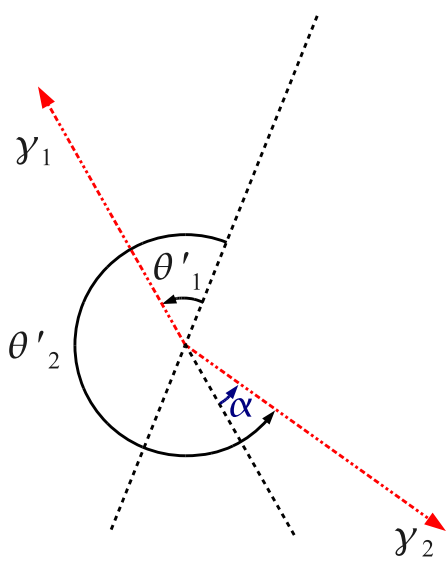

(b) laboratório

Figura 1.1: Relação entre as direções de emissão dos gamas e o momento do centro de massa do par elétron-pósitron nos referenciais do centro de massa e do laboratório (note que, como $\alpha$ está exagerado, os gamas são praticamente colineares no referencial do laboratório). 


$$
\begin{aligned}
\omega^{\prime} & =\gamma \omega(1-\beta \cos \theta) \\
\operatorname{tg} \theta^{\prime} & =\frac{\operatorname{sen} \theta}{\gamma(\cos \theta-\beta)}
\end{aligned}
$$

sendo que

$$
\begin{aligned}
\beta & =\frac{v}{c} \\
\gamma & =\sqrt{\frac{1}{1-\beta^{2}}}
\end{aligned}
$$

onde $v$ é a velocidade relativa entre o referencial do laboratório e o referencial do centro de massa.

Para obter a relação entre a energia dos gamas, o ângulo entre eles e o momento do centro de massa do par elétron-pósitron pode ser feita uma aproximação em primeira ordem em torno de $\beta=0$. Esta aproximação se justifica, pois, como já mencionado, quando o pósitron entra no material ele vai rapidamente para o estado fundamental, devido ao processo de termalização. Portanto, a velocidade do par elétron-pósitron é devida, basicamente, ao movimento do elétron. Como a energia cinética de um elétron $\left(E_{c}\right)$ é da mesma ordem de grandeza da energia de ligação $(B)$, que para os elétrons mais internos é da ordem de $1 \mathrm{keV}$ e para elétrons de condução não excede poucos $e V s$, a expansão até primeira ordem em $\beta$ se justifica. Com essa expansão, tem-se:

$$
\begin{gathered}
\gamma=1+\frac{E_{c}}{m_{0} c^{2}} \approx 1+\frac{B}{m_{0} c^{2}} \\
\gamma \approx 1+\frac{1}{511} \approx 1, \text { ou seja, } \beta \approx 0
\end{gathered}
$$

Assim, multiplicando a equação $1.2 \mathrm{a}$ pela constante de Planck e utilizando a aproximação acima, a energia dos gamas $\left(E_{1,2}\right)$, devido a mudança de referencial entre o laboratório e o centro de massa, pode ser escrita como 


$$
E_{1,2}=m_{0} c^{2} \pm p_{/ /} c
$$

Se for incluída a energia de ligação, obtém-se

$$
E_{1,2}=E_{0} \pm \frac{p_{/ /} c}{2}-\frac{B}{2}
$$

A aproximação em primeira ordem em torno de $\beta=0$ também pode ser utilizada para se obter o ângulo entre os gamas no referencial do laboratório $(\alpha)$. Pela figura 1.1 A relação entre $\alpha, \theta_{1}^{\prime}$ e $\theta_{2}^{\prime}$ é:

$$
\alpha=\theta_{2}^{\prime}-\theta_{1}^{\prime}
$$

Tomando-se a tangente e substituindo a equação $1.2 \mathrm{~b}$.

$$
\operatorname{tg} \alpha=\operatorname{tg}\left(\theta_{2}^{\prime}-\theta_{1}^{\prime}\right) \Rightarrow \alpha=\frac{p_{\perp}}{m_{0} c}
$$

Dessa forma, através das equações 1.3 e 1.4 é possível obter as componentes paralela e perpendicular do momento do par elétron-pósitron, se forem conhecidos a energia e o ângulo dos gamas emitidos.

\subsection{Espectro de coincidência}

Em experimentos de alargamento Doppler são medidas as energias $\left(E_{1,2}\right)$ dos gamas emitidos na aniquilação. O espectro das energias destes gamas é medido em coincidência temporal e é chamado de espectro de coincidência. A figura 1.2 mostra um espectro típico de coincidência temporal. Segundo a equação 1.3 o valor esperado da energia dos gamas medidos no processo de aniquilação é $m_{0} c^{2}-B / 2$ já que o valor médio de $p_{/ /}$é zero. Apesar disso, o termo $\pm p_{/ /} / 2$ faz com que quando um gama tem energia acrescida deste valor o outro gama tem sua energia subtraída deste mesmo valor. Assim, há uma covariância negativa entre $E_{1}$ e $E_{2}$,

Geralmente, a análise dos espectros de coincidência é feita através das projeções deste espectro ao longo das projeções diagonais $E_{1}-E_{2}$ (perfil largo) e $E_{1}+E_{2}$ (perfil estreito) [7] (figuras 1.3 e 1.4). Através da equação 


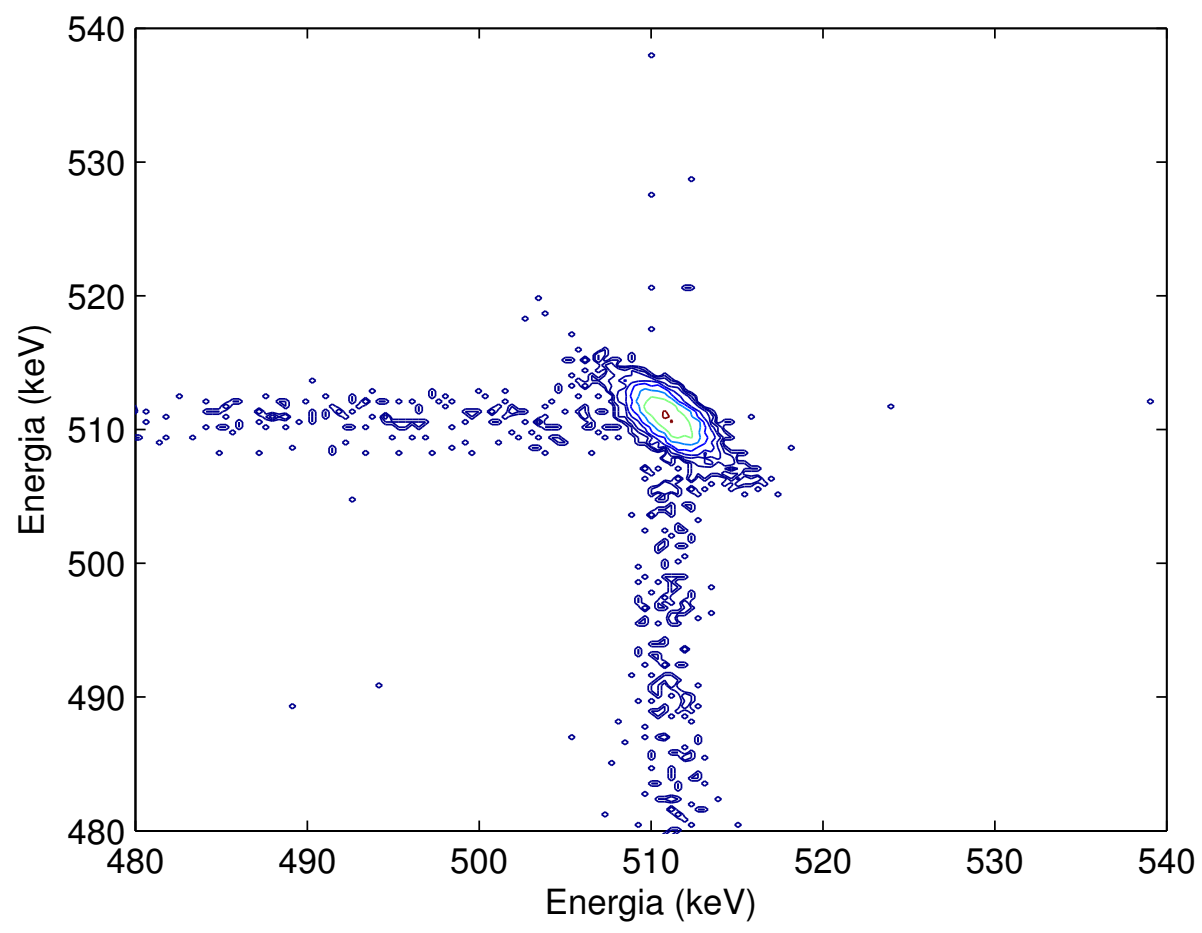

Figura 1.2: Espectro de coincidência obtido sem o uso filtro angular $\left(0^{\circ}\right)$. As curvas correspondem aos níveis 1, 2, 4, 8, 16, 32, 64 e 128. 


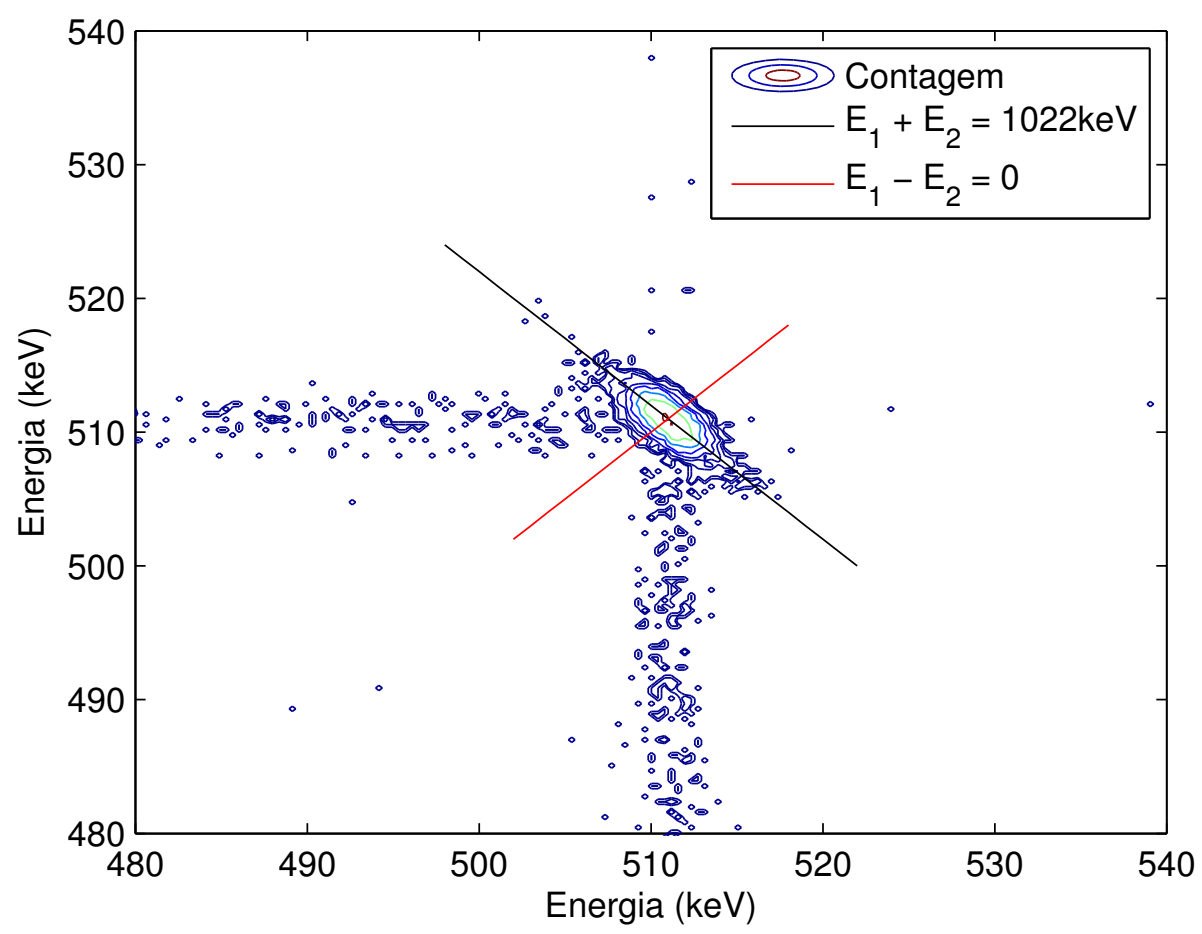

Figura 1.3: Espectro de coincidência obtido sem o uso filtro angular $\left(0^{\circ}\right) \mathrm{e}$ eixos convenientes para a análise. Enquanto a largura da projeção marginal no eixo $E_{1}-E_{2}=$ cte está relacionada com o deslocamento Doppler e com a resolução combinada dos detetores a largura da projeção marginal $E_{1}+$ $E_{2}=$ cte está relacionada apenas a resolução dos detectores. As curvas correspondem aos níveis 1, 2, 4, 8, 16, 32, 64, 128 e 256.

1.5 pode-se ver que o perfil largo (eixo $E_{1}-E_{2}$ ) traz informações sobre o deslocamento Doppler e o perfil estreito (eixo $E_{1}+E_{2}$ ) traz informações sobre a energia de ligação do elétron aniquilado.

$$
\begin{array}{ll}
E_{1}-E_{2}=\quad p_{/ /} \quad & \text { perfil largo } \\
E_{1}+E_{2}=2 m c^{2}-B & \text { perfil estreito }
\end{array}
$$

Para evitar a perda de informação que este procedimento provoca, recentemente, no Laboratório do Acelerador Linear, foi desenvolvido um método 


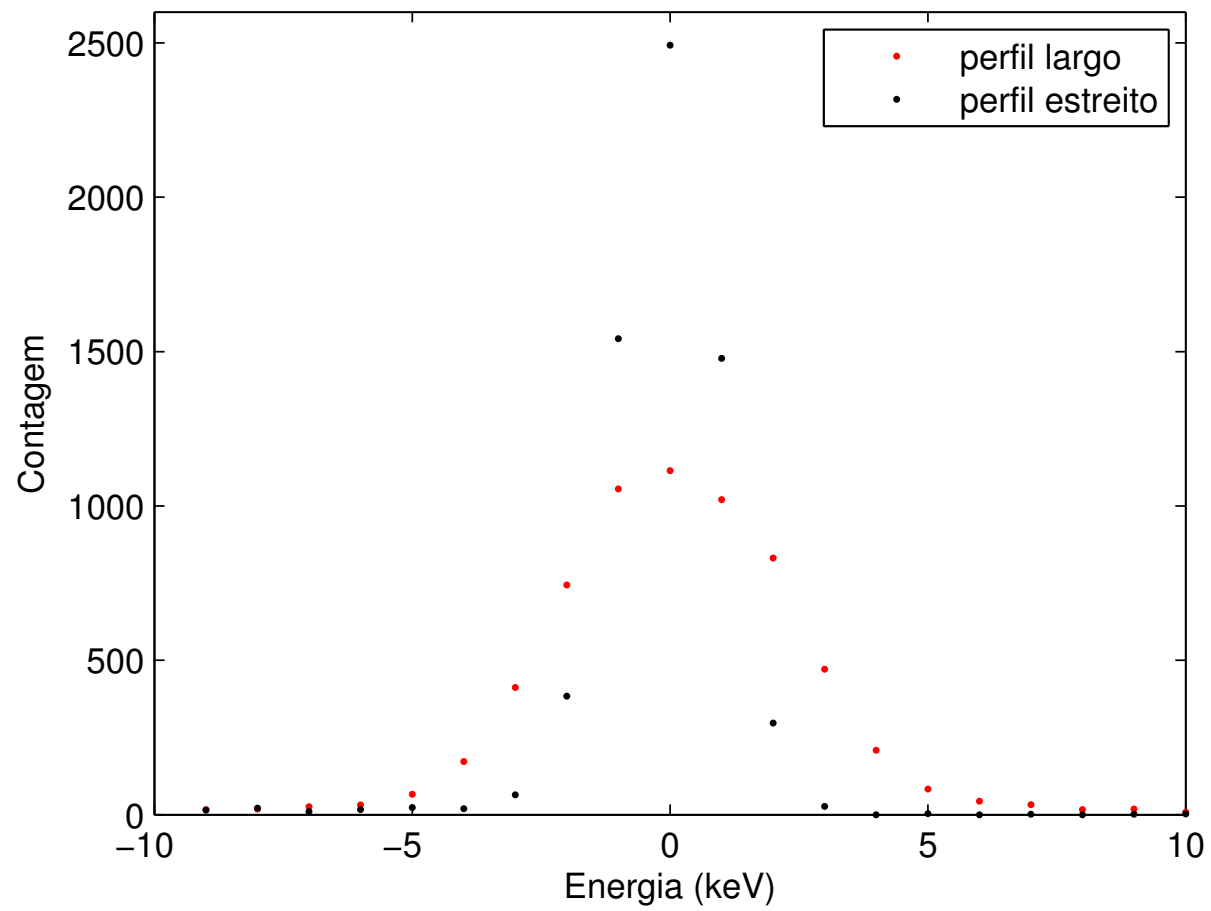

Figura 1.4: Perfil largo (projeção marginal do eixo $E_{1}-E_{2}=$ cte) e estreito (projeção marginal do eixo $E_{1}+E_{2}=c t e$ ) do espectro de coincidência. A largura em excesso na projeção ao longo do eixo $E_{1}-E_{2}=$ cte é devida ao deslocamento Doppler. 
para a análise do espectro de coincidência através do ajuste de funções modelos diretamente aos dados experimentais [4, 5]. Este método permite detalhar melhor aniquilações com elétrons ligados, já que, quando se analisa apenas o espectro de diferença de energia (perfil largo), como é usualmente feito, a informação da energia de ligação é perdida (como pode-se ver na $1.5 \mathrm{a}$ ). $\mathrm{O}$ filtro angular descrito na seção 1.5 é uma alternativa a este procedimento para se estudar as aniquilações com elétrons fortemente ligados. Neste caso, porém, busca-se reduzir a fração de aniquilações com elétrons de valência.

\subsection{Filtro angular}

O filtro angular, figura 1.5, é composto por um colimador com um furo circular (diâmetro $D$ ) e um bloqueio cilíndrico (diametro $d$ ) posicionado a uma distância $r$ da fonte, ambos de chumbo. Essa geometria permite que apenas gamas emitidos com um ângulo de corte maior ou igual a um certo ângulo crítico $\left(\alpha_{c}\right)$ sejam medidos.

$$
\alpha_{c} \approx \frac{d}{2 r}
$$

Segundo a equação 1.4 o ângulo entre os gamas é proporcional à componente perpendicular do momento dos elétrons. Dessa forma, são selecionadas apenas aniquilações com uma quantidade de movimento perpendicular maior ou igual a:

$$
p_{\perp_{c}}=\alpha_{c} m_{0} c
$$

\subsection{Funções densidade de probabilidade de $p_{/ /}$ e $p_{\perp}$}

Para avaliar o efeito da introdução do filtro angular na medida do alargamento Doppler é importante conhecer as funções densidade de probabilidade de $p_{/ /}$e $p_{\perp}$. Em um experimento sem o uso do filtro angular, a medida 


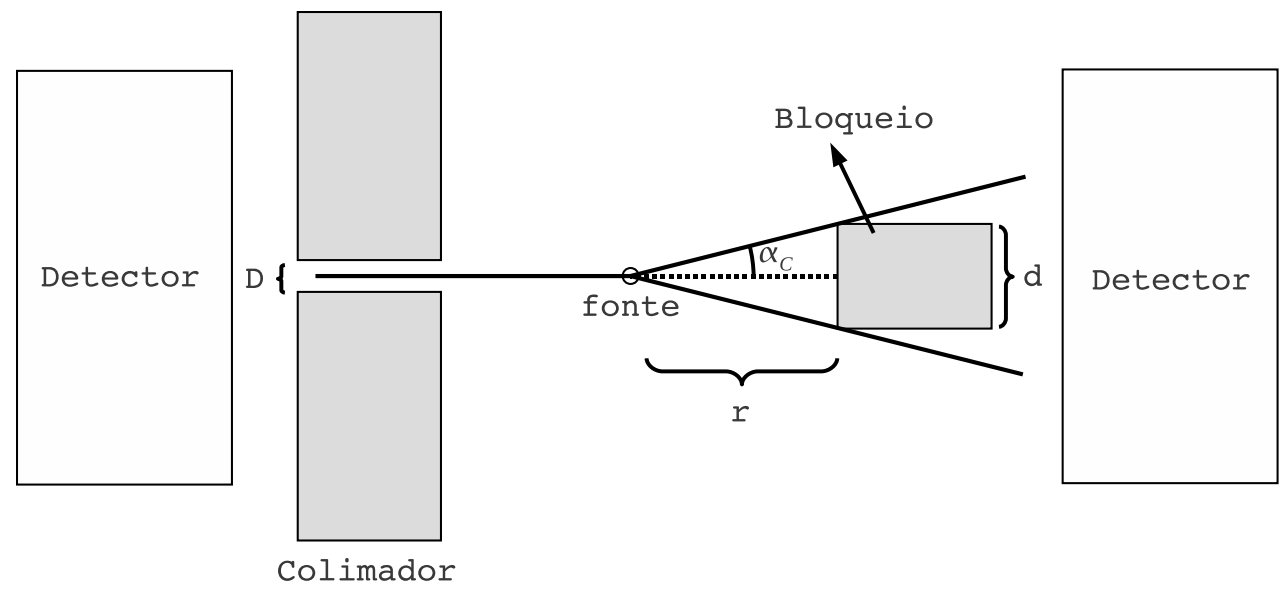

Figura 1.5: Filtro Angular. Um colimador e um bloqueio de chumbo permitiam que apenas fossem detectados eventos cujo ângulo entre os gamas fossem maiores do que um ângulo de corte $\left(\alpha_{C}\right)$ definido pela geometria. A figura está fora de escala para facilitar o entendimento do arranjo

do alargamento Doppler é uma medida direta da $f d p$ de $p_{/ /}$(equação 1.5a). Como todos os ângulos entre os gamas são permitidos, a função densidade de probabilidade de $p_{/ /}$é a $f d p$ marginal:

$$
f\left(p_{/ /}\right)=\int_{0}^{+\infty} g\left(p_{/ /}, p_{\perp}\right) d p_{\perp}
$$

sendo que $g\left(p_{/ /}, p_{\perp}\right)$ é a $f d p$ conjunta de $p_{/ /}$e $p_{\perp}$.

Quando o filtro angular é introduzido, apenas são detectadas aniquilações nas quais $p_{\perp}$ é maior do que um valor crítico $\left(p_{\perp_{c}}\right)$, definido pela geometria do arranjo experimental (equação 1.7). Dessa forma, a $f d p$ de $p_{/ /}$será:

$$
f\left(p_{/ /}\right)=\int_{p_{\perp c}}^{+\infty} g\left(p_{/ /}, p_{\perp}\right) d p_{\perp}
$$

Para se determinar $g\left(p_{/ /}, p_{\perp}\right)$ é necessário conhecer a função densidade de probabilidade do módulo do momento do par elétron-pósitron $h(p)$, que pode ser obtida modelando-se o processo de aniquilação. A seção 3.2 mostra um modelo de $h(p)$, que, apesar de simplificado, apresenta um bom acordo com os dados experimentais.

Definindo um sistema de coordenadas tal que o eixo $z$ seja a direção na 


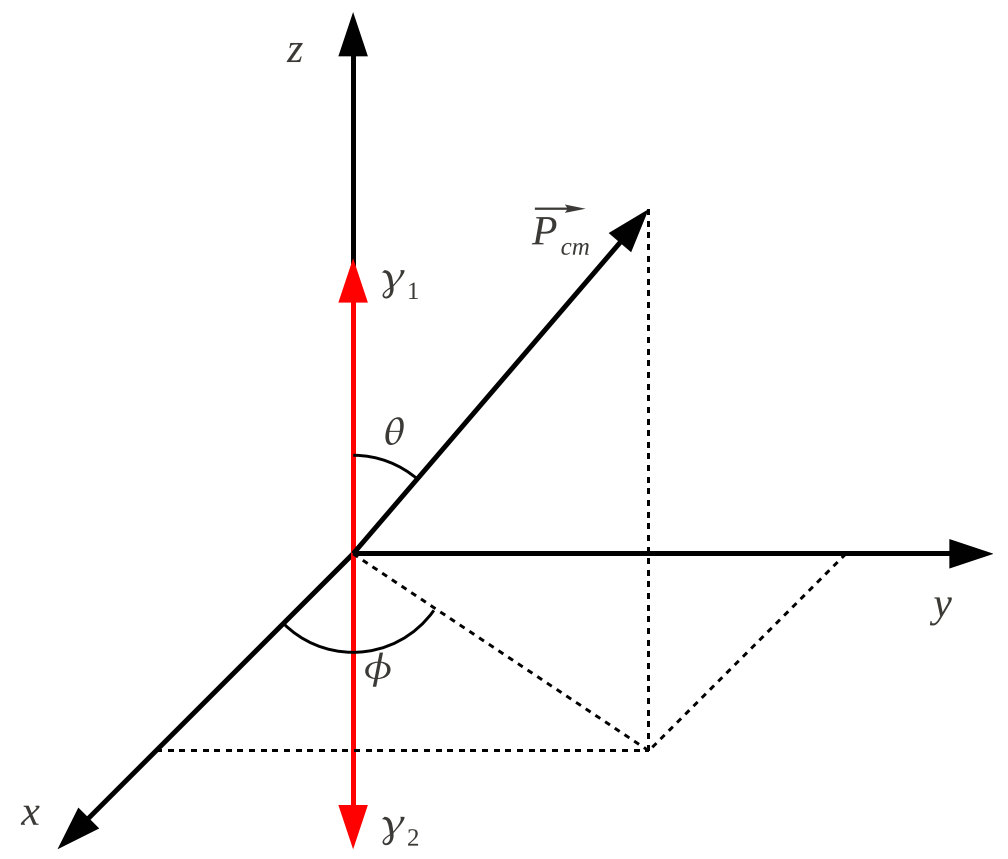

Figura 1.6: Sistema de coordenadas. O eixo $z$ é o eixo definido pela direção de propagação dos gamas. O ângulo $\theta$ é o ângulo entre o eixo $z$ e a direção do momento do centro de massa do par elétron-pósitron

qual foram emitidos os gamas e o ângulo $\theta$ seja definido entre este eixo e o momento do centro de massa do par elétron-pósitron (figura 1.6), a função densidade de probabilidade de $p, \theta$ e $\phi(\Theta(p, \theta, \phi))$ pode ser escrita, devido a isotropia de $h(p)$, como:

$$
\Theta(p, \theta, \phi)=\frac{h(p) \operatorname{sen} \theta}{4 \pi}
$$

Integrando em $\phi$ e fazendo a mudança de variável,

$$
\left\{\begin{array}{l}
p_{\perp}=p \operatorname{sen} \theta \\
p_{/ /}=p \cos \theta
\end{array},\right.
$$

cujo Jacobiano é

$$
\left|\frac{\partial\left(p_{/ /}, p_{\perp}\right)}{\partial(p, \theta)}\right|=p,
$$

obtém-se: 


$$
g\left(p_{/ /}, p_{\perp}\right)=\left.\frac{h(p) \operatorname{sen} \theta}{2 p}\right|_{p_{/ /}, p_{\perp}}=\frac{\left.p_{\perp} h(p)\right|_{p_{/ /}, p_{\perp}}}{2\left(p_{/ /}^{2}+p_{\perp}^{2}\right)} .
$$

Assim, de posse das equações 1.11 e 1.9 é possível, através da modelagem da $f d p$ do módulo do momento dos elétrons, obter a função densidade de probabilidade de $p_{/ /}$e consequentemente da diferença de energia dos gamas (perfil largo). 


\section{Capítulo 2}

\section{Experimental}

As medidas foram realizadas no Laboratório do Acelerador Linear (LAL) do Departamento de Física Experimental do Instituto de Física da USP. Este laboratório dispõe de toda infra estrutura necessária para o experimento sem o uso de grande quantidade de recursos extras. Foram aproveitados tanto os detectores e módulos eletrônicos existentes quanto e eletrônica de aquisição desenvolvida em trabalhos anteriores neste mesmo laboratório.

Um esquema da geometria do arranjo experimental encontra-se na figura 1.5. Em uma breve descrição, os pósitron gerados numa fonte de ${ }^{22} \mathrm{Na}$ eram aniquilados com elétrons em uma camada de alumínio que revestia a fonte. Os gamas emitidos na aniquilação eram selecionados pelo filtro angular e atingiam os detectores. A eletrônica de aquisição garantia que os pulsos obtidos nos detectores estavam em coincidência temporal. Nesta seção serão apresentados, em detalhes, as características deste arranjo.

\subsection{Amostra}

A amostra, de atividade da ordem de $10^{5} \mathrm{~Bq}$, foi construída através do gotejamento de uma solução aquosa inerte contendo ${ }^{22} \mathrm{Na}$ em um envólucro de alumínio, com o uso de uma micropipeta. As vantagens do uso de ${ }^{22} \mathrm{Na}$ como fontes de pósitrons são muitas e estão descritas na seção 2.1.1. O raio da região onde ficou depositado o sódio era de aproximadamente $0,5 \mathrm{~mm}$ e 


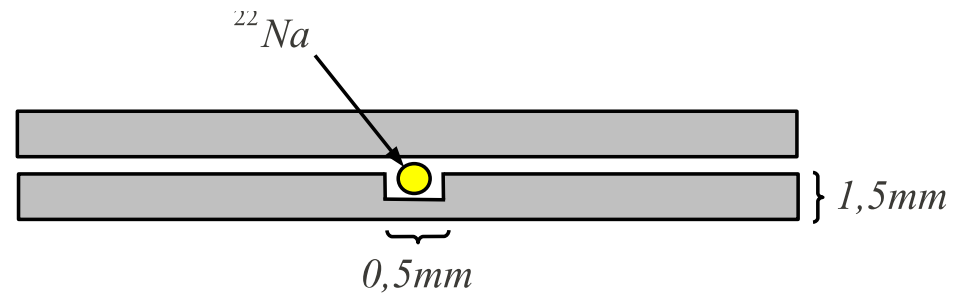

Figura 2.1: Esquema da fonte utilizada. $\mathrm{O}{ }^{22} \mathrm{Na}$ decai emitindo pósitrons que são aniquilados com elétrons do envólucro de alumínio.

a espessura da chapa de alumínio do envólucro era de, aproximadamente, 1,5mm. A figura 2.1 mostra um esquema da fonte.

Considerando-se a distância máxima de penetração de pósitrons em alumínio, que é da ordem de décimo de milímetro [11] para os pósitrons mais energéticos $(\sim 540 \mathrm{keV})$ emitidos pelo ${ }^{22} \mathrm{Na}$, a espessura das folhas garantia que todas as aniquilações ocorreriam no interior da amostra.

A escolha do alumínio como meio para ocorrerem as aniquilações deveu-se à grande quantidade de trabalhos publicados com esse material [12], inclusive alguns do próprio Laboratório do Acelerador Linear [4, 13]. A pureza do material utilizado era superior a 99,99\%

\subsubsection{Fontes de ${ }^{22} \mathrm{Na}$}

Na natureza, as duas principais fontes de pósitrons são decaimentos nucleares $\beta^{+}$e o processo de formação de pares $e^{+} e^{-}$por gamas com energia maior do que $2 m_{0} c^{2}$. Em experimentos de aniquilação a fonte mais comumente empregada é ${ }^{22} N a$. A principal razão para esta escolha é a fácil manipulação de soluções aquosas contendo o sódio e sua meia vida relativamente alta (2,6 anos). Além disso, no decaimento deste radioisótopo é emitido, quase simultaneamente com o pósitron $(\sim 3 p s)$, um gama de $1274 k e V$. Este gama é essencial na técnica de Espectroscopia de Vida Média, pois indica o tempo em que foi criado o pósitron, servindo de start para a eletrônica do experimento [6. A figura 2.2 mostra o esquema de decaimento desse radioisótopo [14]. 


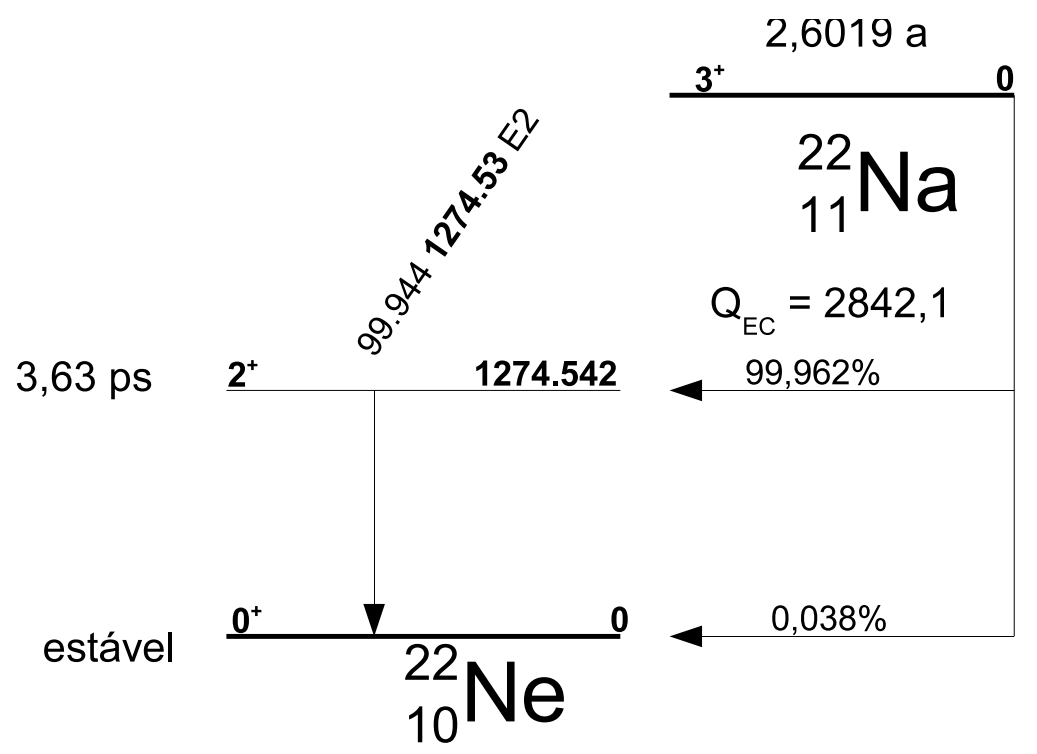

Figura 2.2: Esquema de decaimento do ${ }^{22} \mathrm{Na}$ para o ${ }^{22} \mathrm{Ne}$. Após o decaimento $\beta^{+}$(meia vida $\left.\sim 3,6 \mathrm{ps}\right)$ é emitido um gama de energia $\sim 1274,5 \mathrm{keV}$.

\subsection{Filtro Angular}

O filtro angular, descrito na seção 1.5, é composto basicamente de duas peças. Um colimador de comprimento $135 \mathrm{~mm}$, com orifício circular de diâmetro $D=3,2 \mathrm{~mm}$, e um bloqueio cilíndrico de chumbo de comprimento $120 \mathrm{~mm}$ e diâmetros que podiam ser $d=5,6 \mathrm{~mm}$ e $d=8,0 \mathrm{~mm}$.

O ângulo de corte (figura 1.5) era definido pelo raio do bloqueio cilíndrico e a distância $(r)$ entre este bloqueio e a fonte (equação 1.6).

Para que a fonte radioativa, o colimador e o bloqueio cilíndrico ficassem alinhados no mesmo eixo de simetria, foi construído um sistema constituído por uma guia e suportes para posicionar estas peças e a fonte radioativa. A figura 2.3 mostra uma foto do arranjo experimental.

Foi acoplado ao suporte da fonte um posicionador $x y$ de forma que a amostra pudesse ser posicionada ao longo do eixo de simetria definido entre colimador e o bloqueio. O alinhamento da fonte era feito com o auxílio de um laser. 




Figura 2.3: Arranjo Experimental. A Amostra radioativa era posicionada através de um posicionador $x y$ no eixo formado pelo colimador de chumbo (canto inferior direito) e pelo bloqueio angular (canto superior esquerdo). Uma guia permitia o alinhamento mecânico das peças. 


\subsubsection{Avaliação da transmissibilidade do filtro angular}

Se a fonte radioativa fosse puntiforme, o alinhamento das peças que compõe o filtro angular fosse perfeito e não existisse a possibilidade de um gama atravessar a blindagem e ainda assim ser detectado, então a transmissibilidade do filtro seria uma função degrau do ângulo entre os gamas. Ou seja, não seria detectado nenhum evento abaixo do ângulo de corte, definido pela equação 1.6 e, a partir desse ângulo, todos os gamas que fossem na direção dos detectores seriam detectados. Porém, como a fonte não é puntiforme e há incertezas no alinhamento das peças, a transmissibilidade do filtro é uma função suave do ângulo entre os gamas. Para avaliar este efeito foi feita uma simulação usando técnicas de Monte Carlo.

A simulação, basicamente, gerava um ponto na amostra e dois pontos numa região próxima aos detectores. Estes pontos definiam as trajetórias e o ângulo entre os gamas. Caso alguma trajetória passasse por algum colimador ou bloqueio, era calculado qual a distância que cada gama percorreria no chumbo e qual a probabilidade dele interagir com este material. Foi utilizado o critério de, caso um gama interagisse com a blindagem, ele seria computado como não detectado. Assim, era possível saber, em função do ângulo entre os gamas, a transmissibilidade do filtro. Se o número de gamas detectados para um dado ângulo for $N_{\text {det }}(\alpha)$ e o de bloqueados pelo filtro for $N_{b l o q}(\alpha)$, então a transmissibilidade $(T(\alpha))$ será:

$$
T(\alpha) \propto \frac{N_{d e t}(\alpha)}{N_{\text {det }}(\alpha)+N_{b l o q}(\alpha)}
$$

A figura 2.4 mostra um resultado típico da simulação.

Através desta simulação foram estimados os efeitos de diversos fatores que influenciavam na largura da função transmissibilidade. O principal destes fatores era o perfil de atividade da amostra. O fato região onde foi gotejada a solução contendo ${ }^{22} \mathrm{Na}$ ter dimensão de $\sim 0,5 \mathrm{~mm}$, como pode ser visto na figura 2.1 somado ao fato do pósitron penetrar no alumínio uma distância da ordem de décimo de milímetro (como já discutido na secção 2.1), faz com que a região de onde os dois gamas provenientes da aniquilação se originam não possa ser considerada puntiforme. A incerteza angular no ângulo de corte, 


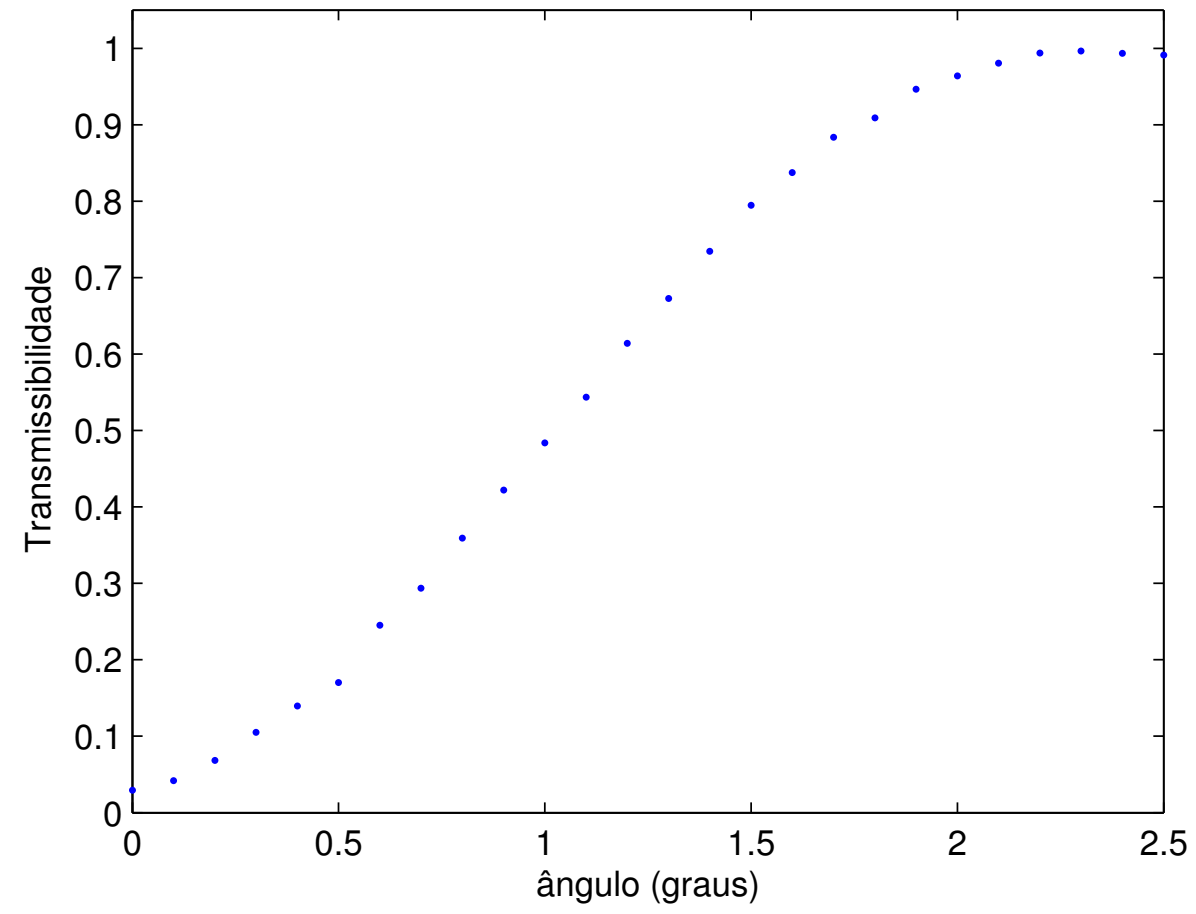

Figura 2.4: Exemplo de transmissibilidade calculada pelo método de Monte Carlo. A geometria do arranjo foi ajustada para um ângulo de corte de $1,2^{\circ}$. As distâncias foram $r=19,2 \mathrm{~cm}, d=8,0 \mathrm{~mm}$ e $D=3,2 \mathrm{~mm}$, segundo a convenção da figura 1.5 . 
devido a este fator era da ordem de $0,5^{\circ}$, variando conforme a geometria do arranjo.

O segundo fator mais relevante na determinação da largura da função transmissibilidade era o raio do colimador. Porém, nesse caso, há um compromisso entre a taxa de contagens e a incerteza no ângulo de corte. Se o raio do colimador for muito pequeno, objetivando uma largura pequena na função transmissibilidade, a taxa de contagens é muito pequena, já que a área efetiva do detector, atrás do colimador, é reduzida. Por outro lado, se o raio do colimador é exagerado, aumentando-se o número de contagens, a incerteza no ângulo de corte é grande. Para o colimador utilizado (cujo raio era de $D=3,2 \mathrm{~mm}$ ) a incerteza angular era dá ordem de $0,2^{\circ}$.

Como o perfil de atividade da amostra era o principal parâmetro para determinação da transmissibilidade do filtro, foi feita uma medida experimental desta grandeza para ser incluída na simulação. Para isso foi montado o arranjo mostrado na figura 2.5. A fonte radioativa era posicionada na frente de um colimador de chumbo com uma fenda fina $(1 \mathrm{~mm})$ e um detector HPGe. A fonte era movida em passos de $0,5 \mathrm{~mm}$ e era observada a taxa de eventos no detector. Foram feitas duas medidas em dois eixos ortogonais que passavam pelo centro da amostra para medida de uma eventual assimetria no se perfil de atividade. Como os dados obtidos nas duas medidas eram muito parecidos, eles foram incluídos em um único ajuste.

Para o perfil da amostra ser incluído na simulação a taxa de contagens $(I(x))$ foi modelada como duas gaussianas centradas no mesmo ponto, mas com larguras diferentes e um fundo linear $(F)$.

$$
I(x)=\frac{a_{1}}{\sqrt{2 \pi} \sigma_{1}} \exp \left[-\frac{\left(x-x_{0}\right)^{2}}{2 \sigma_{1}^{2}}\right]+\frac{a_{2}}{\sqrt{2 \pi} \sigma_{2}} \exp \left[-\frac{\left(x-x_{0}\right)^{2}}{2 \sigma_{2}^{2}}\right]+F
$$

A figura 2.6 mostra os dados obtidos e a função ajustada. Os parâmetros ajustados pelo Método dos Mínimos Quadrados encontram-se na tabela 2.1.

Obviamente, a dispersão dos pontos é muito maior do que a barra de incerteza. Mas o interesse, neste ajuste, era apenas obter uma estimativa de função analítica para o perfil da amostra para ser incluída na simulação. 

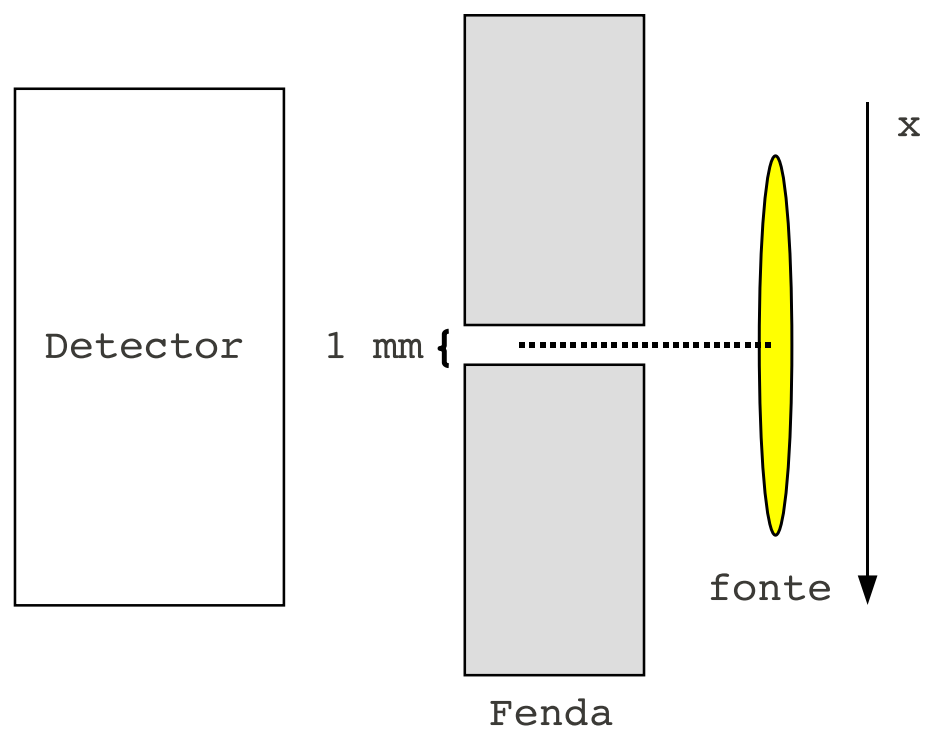

Figura 2.5: Arranjo experimental para avaliação do perfil de atividade da amostra. Foi medida a taxa de contagens no detector em função da posição da fonte de ${ }^{22} \mathrm{Na}(x)$.

$$
\begin{array}{cc}
a_{1}=97,1(31) \text { contagens.mm } / \mathrm{s} & a_{2}=66,6(44) \text { contagens.mm } / \mathrm{s} \\
s_{1}=0,831(12) \mathrm{mm} & s_{2}=2,39(20) \mathrm{mm} \\
\hline
\end{array}
$$

Tabela 2.1: Parâmetros ajustados pelo Método dos Mínimos Quadrados da função descrita pela equação 2.2 aos dados da figura 2.6. 


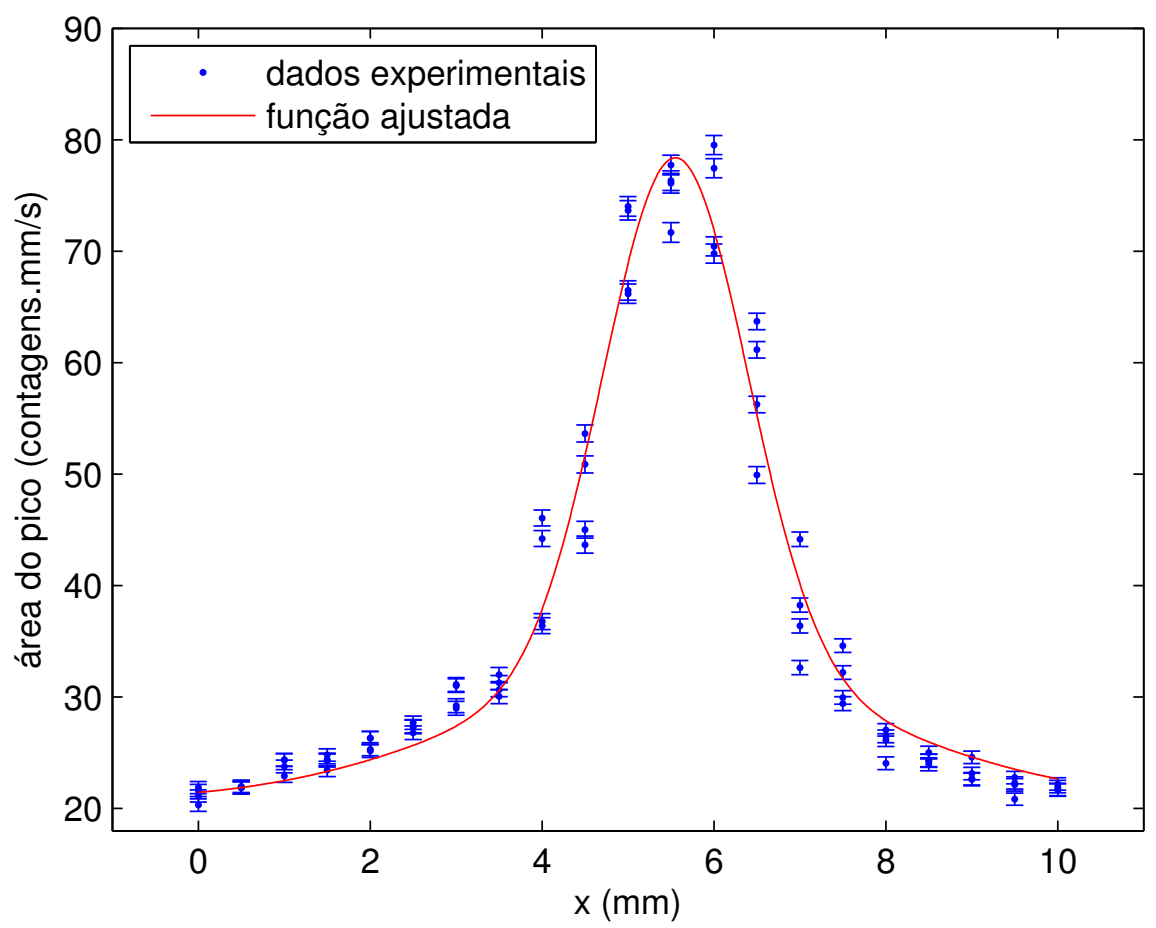

Figura 2.6: Dados experimentais e função ajustada para avaliação do tamanho e forma da fonte. 
Não havia necessidade de conhecer, exatamente, a função modelo que representava esse perfil. Além disso, a incerteza na taxa foi estimada apenas pela flutuação estatística do número de eventos medido em cada posição da fenda. A incerteza no eixo $x$ (posição da amostra) não foi considerada.

\subsection{Detectores}

Para medida de energia foram utilizados dois detectores de germânio hiperpuro (HPGe). Esse tipo de detector é constituído, basicamente, de um cristal semicondutor de Germânio que é mantido a alta tensão e em baixa temperatura. Como o cristal é mantido a baixa temperatura, todos os elétrons estão em seus níveis de valência. Quando um fóton interage com o cristal, por meio de efeito fotoelelétrico, ou espalhamento Compton, um elétron é promovido para a camada de condução e um par elétron-buraco é criado.

Caso a interação do fóton com o cristal seja por meio de efeito fotoelétrico, a energia do elétron promovido é proporcional a energia do fóton incidente. Este elétron, altamente energético $(E \approx 1 M e V)$, ao migrar para a banda de condução gera outros pares elétrons buracos, formando uma nuvem. Os elétrons desta nuvem são, então, arrastados para o ânodo e os buracos para o cátodo do detector. O sinal então coletado é proporcional a energia do fóton incidente no detector [15].

Nesse experimento foram utilizados dois detectores, de volumes $196 \mathrm{~cm}^{3} \mathrm{e}$ $101 \mathrm{~cm}^{3}$. Foram escolhidos detectores de volumes relativamente grandes pois, devido ao uso do filtro angular, a taxa de eventos era baixa (da ordem de 1 contagem/s). Para calibração de energia foram utilizadas as contagens acidentais (já que o sistema de aquisição só registrava eventos em coincidência) de fontes de ${ }^{133} \mathrm{Ba}$ e ${ }^{137} \mathrm{Cs}$. Essas fontes foram escolhidas por apresentar picos intensos com energia não muito distantes de $511 \mathrm{keV}$.

A figura 2.3 mostra um espectro obtido com um dos detectores. 


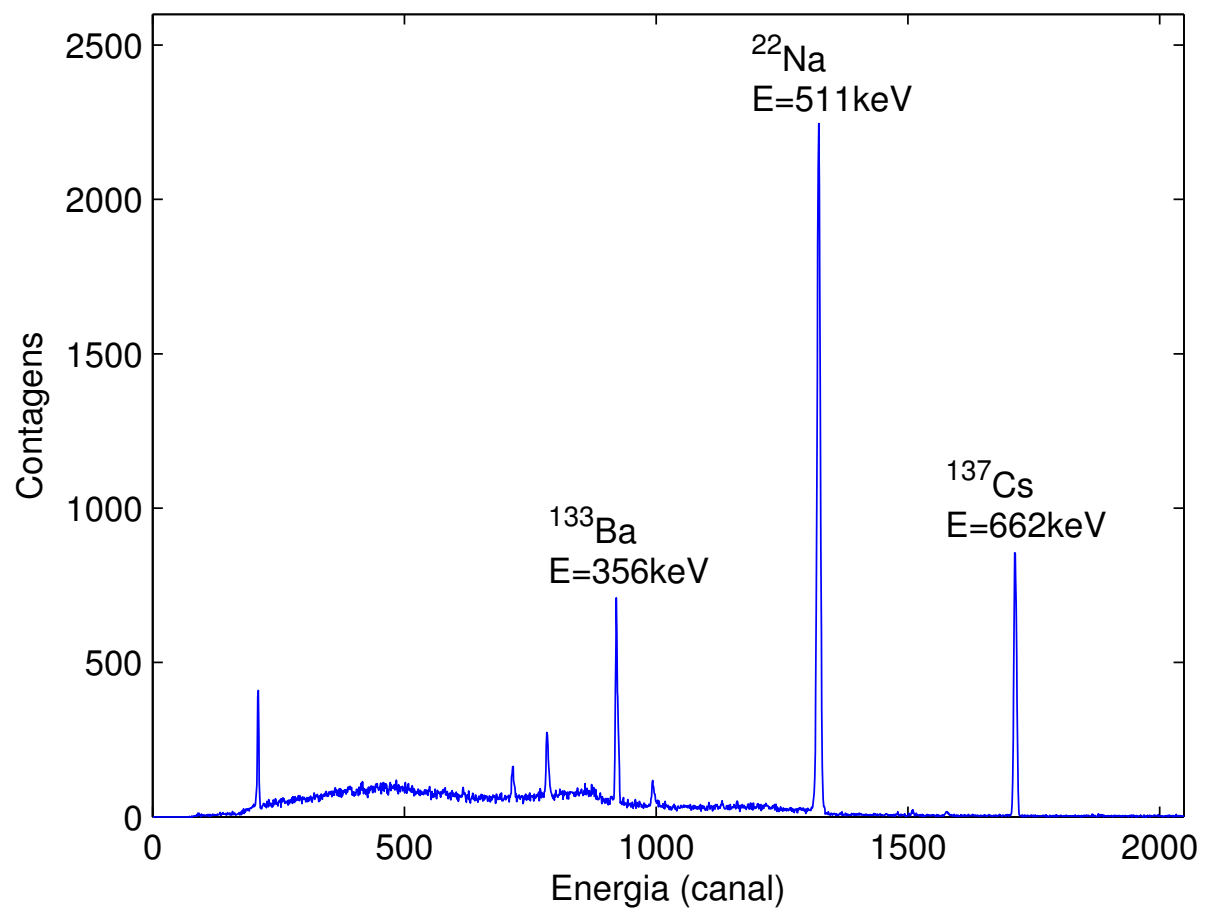

Figura 2.7: Espectro obtido com um dos detectores. Para calibração de energia foram utilizadas coincidências acidentais com fontes de ${ }^{133} \mathrm{Ba}$ e ${ }^{137} \mathrm{Cs}$. 


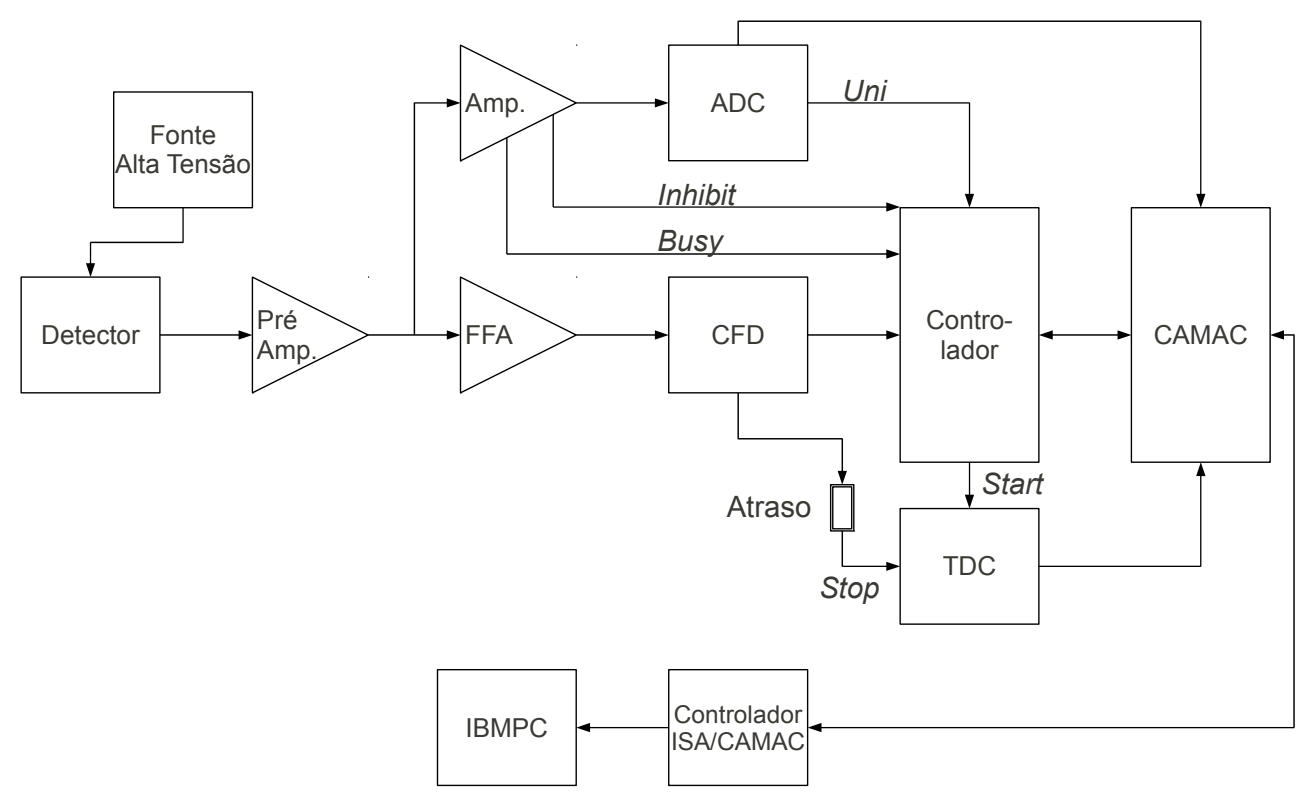

Figura 2.8: Esquema de montagem do sistema Multidetector. O sinal que chega ao detector é dividido em duas vias. Uma (eletrônica rápida) é responsável por determinar o tempo que o fóton chegou ao detector e outra (eletrônica lenta) que é responsável por determinar a energia deste fóton.

\subsection{Sistema Multidetector}

O sistema multidetector foi desenvolvido no Laboratório do Acelerador Linear com o objetivo de fazer medidas em coincidência com até quatro pares de detector. A figura 2.8 mostra o esquema eletrônico do sistema [16].

Em uma breve descrição, o sinal elétrico medido no detector é enviado a um pré amplificador. O sinal é então dividido em duas vias, uma eletrônica rápida, utilizada para fazer a coincidência temporal e uma eletrônica lenta, onde é medida a energia do fóton.

Na linha lenta o sinal é enviado a um amplificador lento, que, além de amplificar o sinal que é enviado ao conversor analógico digital (ADC), emite um sinal de busy para o controlador. Além disso, caso haja empilhamento, 
é emitido um sinal de inhibit fazendo com que o sistema seja reiniciado. O sinal só será registrado pelo ADC caso o sinal de busy esteja ativado e o de inhibit desativado para o número de detectores desejados.

Na linha rápida o sinal é enviado a um amplificador rápido (FFA) e então a um discriminador rápido (CFD). O sinal de tempo gerado pelo CFD é então dividido em duas partes. Uma vai para o controlador e é utilizado para o start do conversor tempo digital (TDC) e outra passa por um cabo de atraso e serve para o stop do TDC.

A saída do multidetector é então enviada a um controlador ISA/CAMAC e então enviada a um computador. Esta saída é composta de arquivos tipo fila, onde se encontram a energia e o tempo de cada evento, em canais, e qual par de detectores foi responsável pela coincidência. No caso deste experimento foram utilizados apenas um par de detectores.

\subsection{Medidas realizadas}

Foram realizados 17 séries de medidas totalizando 320 horas de experimento. Os ângulos de corte variaram de $0,28^{\circ}$ até $1,20^{\circ}$. Também foram medidos espectros com o colimador em um dos detectores, mas sem o bloqueio no outro. A essas medidas foi atribuído o ângulo de $0^{\circ}$, ou seja, sem corte algum. Das 17 medidas obtidas 3 não puderam ser utilizadas devido a instabilidades da eletrônica do sistema. 


\section{Capítulo 3}

\section{Dados obtidos e Análise}

Neste capítulo serão apresentados e analisados os dados obtidos neste experimento. Primeiramente, é feita uma análise simples destes dados, sem o ajuste de qualquer função modelo. Está análise permite obter características importantes do funcionamento do filtro angular. Em seguida, encontra-se uma modelagem deste experimento a partir das funções densidade de probabilidade descritas na seção 1.6, levando-se em conta a transmissibilidade do filtro, discutida na seção 2.2.1. Os resultados previstos por este modelo apresentam ótimo acordo com os dados experimentais. Já na seção 3.3 encontra-se o ajuste dos dados experimentais através de funções modelos.

\subsection{Resultados obtidos}

Como já mencionado, os dados obtidos consistem dos espectros coincidência para os diversos ângulos medidos. A figura 3.1 mostra um espectro de coincidência para um ângulo de corte de $0,42^{\circ}$ graus.

A figura 3.2 apresenta os espectros da diferença de energia. A escala escolhida foi a raiz quadrada da taxa pois, como a função de probabilidade do número de contagens é Poisson, nesta escala a incerteza de todos os dados é, aproximadamente, a mesma, como pode ser visto na propagação: 




Figura 3.1: Espectro de coincidência obtido com o uso filtro angular $\left(0,42^{\circ}\right)$. As curvas correspondem aos níveis 1, 2, 4, 8, 16, 32 e 64 . 


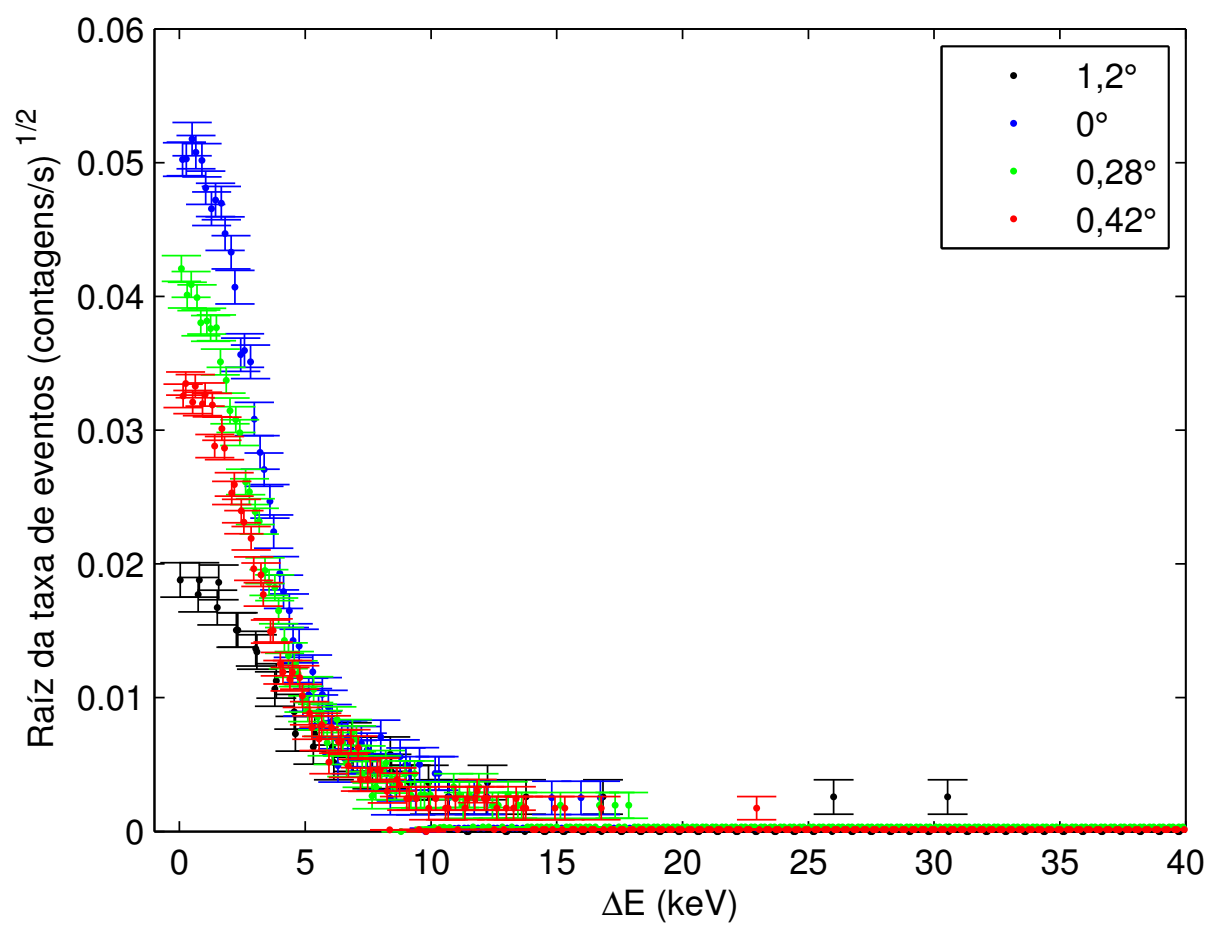

Figura 3.2: Espectros da diferença de energia $\left(E_{1}-E_{2}\right)$ para diferentes ângulos de corte $\left(\alpha_{c}\right)$ de $0^{\circ}, 0,28^{\circ}, 0,42^{\circ}, 1,2^{\circ}$. Quanto maior o ângulo filtrado, maior a redução na taxa de aniquilação para elétrons de baixos momentos. Para elétrons de altos momentos a redução é muito menor. Isto evidencia o funcionamento do filtro angular.

$$
\begin{aligned}
y & =\sqrt{N} \\
\sigma_{y} & =\frac{\partial y}{\partial N} \cdot \sigma_{N} \\
\sigma_{y} & \approx 0,5 .
\end{aligned}
$$

Esta incerteza, 0,5, é a mesma independente do número de eventos observados e vale inclusive quando o número de eventos observados é nulo.

Na figura 3.2 fica evidente a eficácia do filtro angular. De um modo geral houve redução da taxa de contagens para todas as diferenças de energia 




Figura 3.3: Espectros da diferença de energia para diferentes ângulos de corte $\left(\alpha_{c}\right)$ de $0^{\circ}, 1,2^{\circ}$. Escala logarítmica (Os valores indicados foram obtidos dos dados brutos relocando-se o espectro para intervalos do histograma de $0,5 \mathrm{keV}$, usando o procedimento da referência [17]).

quando comparam-se os espectros com ângulo de corte $\left(\alpha_{c}\right)$ diferentes de zero com aquele em que não havia bloqueio $\left(\alpha_{c}=0\right)$. Porém, essa redução foi muito mais intensa para valores de $\Delta E$ pequenos, que correspondem a baixos momentos (equação 1.5a) e, portanto, elétrons fracamente ligados, do que para valores de $\Delta E$ grandes, correspondente a elétrons fortemente ligados. Outra maneira usual de apresentar estes resultados é usando escala logarítmica e normalizando pelo valor máximo de cada espectro. A figura 3.3 mostra estes resultados, apenas para os ângulos críticos extremos $\left(0^{\circ} \mathrm{e}\right.$ $\left.1,2^{\circ}\right)$. Nesta figura o funcionamento do filtro angular também é evidente.

Tomando-se apenas os ângulos de corte extremos $\left(0^{\circ}\right.$ e $\left.1,2^{\circ}\right)$ para $\Delta E$ maiores do que $6 \mathrm{keV}$ a taxa de eventos foi reduzida apenas de um fator 1,8 enquanto para $\Delta E$ menores do que $6 \mathrm{keV}$ a redução foi de um fator 12 . Isso 
demonstra claramente que o filtro angular está selecionando aniquilações com elétrons fortemente ligados, como era esperado.

Outro resultado que pode ser obtido diretamente dos dados experimentais, sem o ajuste de qualquer função modelo é a dispersão do espectro de diferença de energia $\left(\sigma_{\Delta E}\right)$, que está relacionada com o valor esperado de $p_{/ /}^{2}$. Se for considerado um erro experimental $\delta_{1}$ no valor de $E_{1}$ e um erro experimental $\delta_{2}$ no valor de $E_{2}$, as equações 1.5 podem ser escritas como:

$$
\begin{aligned}
& E_{1}-E_{2}=p_{/ /} c+\left(\delta_{1}-\delta_{2}\right) \\
& E_{1}+E_{2}=2 m c^{2}+B+\left(\delta_{1}+\delta_{2}\right)
\end{aligned}
$$

Dessa forma, o valor esperado da dispersão da projeção larga é:

$$
\begin{aligned}
& \sigma_{\Delta E}^{2}=<\Delta E^{2}>-<\Delta E>^{2} \\
& \sigma_{\Delta E}^{2}=<p_{/ /}^{2}>c^{2}+\underbrace{\left(<\delta_{1}^{2}>+<\delta_{2}^{2}>\right)}_{\text {resolução combinada dos detectores }}
\end{aligned}
$$

uma vez que $<\delta_{1}>=<\delta_{2}>=<\delta_{1} \delta_{2}>=0$.

A resolução combinada dos detectores pode ser obtida através da largura da projeção estreita do espectro de coincidência, desprezando-se a energia de ligação:

$$
\begin{aligned}
\sigma_{E_{1}+E_{2}}^{2} & =<\left(E_{1}+E_{2}\right)^{2}>-<E_{1}+E_{2}>^{2} \\
\sigma_{E_{1}+E_{2}}^{2} & =\left(<\delta_{1}^{2}>+<\delta_{2}^{2}>\right)
\end{aligned}
$$

Dessa forma, o desvio padrão adicional $\left(\sigma_{\text {adic }}\right)$ do espectro de diferença de energia, cuja origem é o deslocamento Doppler, é proporcional ao valor esperado de $<p_{/ /}^{2}>$

$$
\sigma_{\text {adic }} \equiv \sqrt{\left(\sigma_{\Delta E}\right)^{2}-\sigma_{E_{1}+E_{2}}^{2}}=\sqrt{<p_{/ /}^{2}>c}
$$






Figura 3.4: Largura adicional do espectro de $\Delta E$ em função do ângulo de corte. Quanto maior o ângulo de corte maior o valor de $\sigma_{\text {adic }}=\sqrt{<p_{/ /}^{2}>c}$. Ou seja, as aniquilações estão se dando com elétrons mais ligados.

A figura 3.4 mostra os resultados obtidos. Este resultado também mostra claramente a funcionalidade do filtro angular. Quanto maior o ângulo de corte maior o valor de $\sigma_{\text {adic }}$, o que implica valores maiores de $\left\langle p_{/ /}^{2}>\right.$, ou seja, quanto maior o ângulo de corte maior a contribuição relativa das aniquilações que ocorrem com elétrons mais ligados.

\subsection{Modelagem}

Conhecendo-se a função densidade de probabilidade de $p_{/ /}$e $p_{\perp}$ é possível calcular o valor esperado de $<p_{/ /}^{2}>$ como: 


$$
<p_{/ /}^{2}>=\frac{\int_{-\infty}^{+\infty} \int_{p_{\perp_{c}}}^{+\infty} p_{/ /}^{2} g\left(p_{/ /}, p_{\perp}\right) d p_{\perp} d p_{/ /}}{\int_{-\infty}^{+\infty} \int_{p_{\perp_{c}}}^{+\infty} g\left(p_{/ /}, p_{\perp}\right) d p_{\perp} d p_{/ /}}
$$

sendo que $g\left(p_{/ /}, p_{\perp}\right)$ pode ser calculado a partir da função densidade de probabilidade de momento $h(p)$, através da equação 1.11 .

Foi feita uma modelagem simples para se obter $g\left(p_{/ /}, p_{\perp}\right)$ no alumínio. Esta função foi avaliada como a soma das fdps de todos os i-ésimo elétrons ligados ou da banda de condução,

$$
g\left(p_{/ /}, p_{\perp}\right)=\sum_{i} A_{i} \frac{p_{\perp} h_{i}(p)}{\left(p_{/ /}^{2}+p_{\perp}^{2}\right)}
$$

sendo que $A_{i}$ é a intensidade relativa da aniquilação elétron-pósitron com o i-ésimo elétron.

Para elétrons de condução, $h(p)$ foi aproximada por distribuições de Fermi, ou seja:

$$
h(p) \propto\left\{\begin{array}{c}
p^{2} \text { se } p \leq p_{\text {Fermi }} \\
0 \text { se } p>p_{\text {Fermi }}
\end{array}\right.
$$

Para elétrons ligados $h(p)$ foi estimada como gaussianas de média zero e desvio padrão $\sigma_{p}$ :

$$
h(p) \propto \exp \left(-\frac{p^{2}}{2 \sigma_{p}}\right)
$$

onde $\sigma_{p}$ foi estimado como:

$$
\sigma_{p}=\sqrt{<p^{2}>-<p>^{2}} \approx \sqrt{2 m E_{c}}
$$

sendo que $E_{c}$ é a energia cinética do elétron, considerando-se elétrons não relativísticos.

Supondo um potencial central e usando o teorema do virial, finalmente obtém-se

$$
\sigma_{p} \approx \sqrt{2 m B}
$$




\begin{tabular}{ccccc}
\hline Elétron & $\begin{array}{c}\text { Momento } \\
\text { máximo } \\
\left(10^{-3} m_{0} c\right)\end{array}$ & $\begin{array}{c}\text { Energia } \\
\text { máxima } \\
(\mathrm{keV})\end{array}$ & $\begin{array}{c}\text { Angulo } \\
\text { máximo } \\
\text { (graus) }\end{array}$ & $\begin{array}{c}\text { Intensidade } \\
\text { da aniquilação } \\
(\%)\end{array}$ \\
\hline Valência 1 & 6,8 & 0,012 & 0,4 & 90 \\
Valência 2 & 12 & 0,037 & 0,7 & 1.4 \\
Valência 3 & 18,8 & 0,083 & 1,0 & 0.1 \\
\hline Elétron & $\sqrt{p^{2}}$ & Energia & Ângulo & Intensidade \\
& & de ligação & médio & da aniquilação \\
& $\left(10^{-3} m_{0} c\right)$ & $(k e V)$ & (graus) & $(\%)$ \\
\hline $2 \mathrm{p}$ & 17 & 0,07 & 0,9 & 6 \\
$2 \mathrm{~s}$ & 22 & 0,12 & 1,2 & 2,5 \\
$1 \mathrm{~s}$ & 77 & 1,5 & 4,4 & 0.015 \\
\hline
\end{tabular}

Tabela 3.1: parâmetros utilizados para a estimativa de $f(p)$

onde B é a energia de ligação do elétron.

Foram considerados três tipos de elétrons de valência, um para cada momento de Fermi, e três tipos de elétrons de ligados, $1 s$, $2 s$ e $2 p$. As intensidades relativas de aniquilação $\left(A_{i}\right)$, os momentos de Fermi $\left(p_{F e r m i}\right)$ e as energias de ligações $(B)$ dos elétrons no alumínio, foram tomadas como as médias dos valores das referências [7, 4, 12, 18]. Os valores utilizados encontram-se na tabela 3.1.

A figura 3.5 mostra a função densidade de probabilidade de $p_{/ /}$obtida através dessa modelagem quando não é introduzido nenhum filtro angular. Apesar deste modelo ser bastante simplificado, o resultado obtido é muito similar ao obtido usando uma modelagem muito mais detalhada, como por exemplo o calculado na referência [7] (figura 3.6). Isto indica que o modelo simplificado, usado neste trabalho, é suficiente para analisar os resultados.

A figura 3.7 mostra os resultados obtidos para os ângulos utilizados neste experimento. Nesta figura é possível avaliar o funcionamento do filtro angular. Quando não há filtro angular, o espetro obtido é muito similar aos obtidos em outras referências. Quando o filtro é inserido, mesmo com um pequeno ângulo $\left(0,28^{\circ}\right)$, a porção do espectro devido aos elétrons de valência é reduzida drasticamente. Quando o ângulo do filtro é um pouco maior 


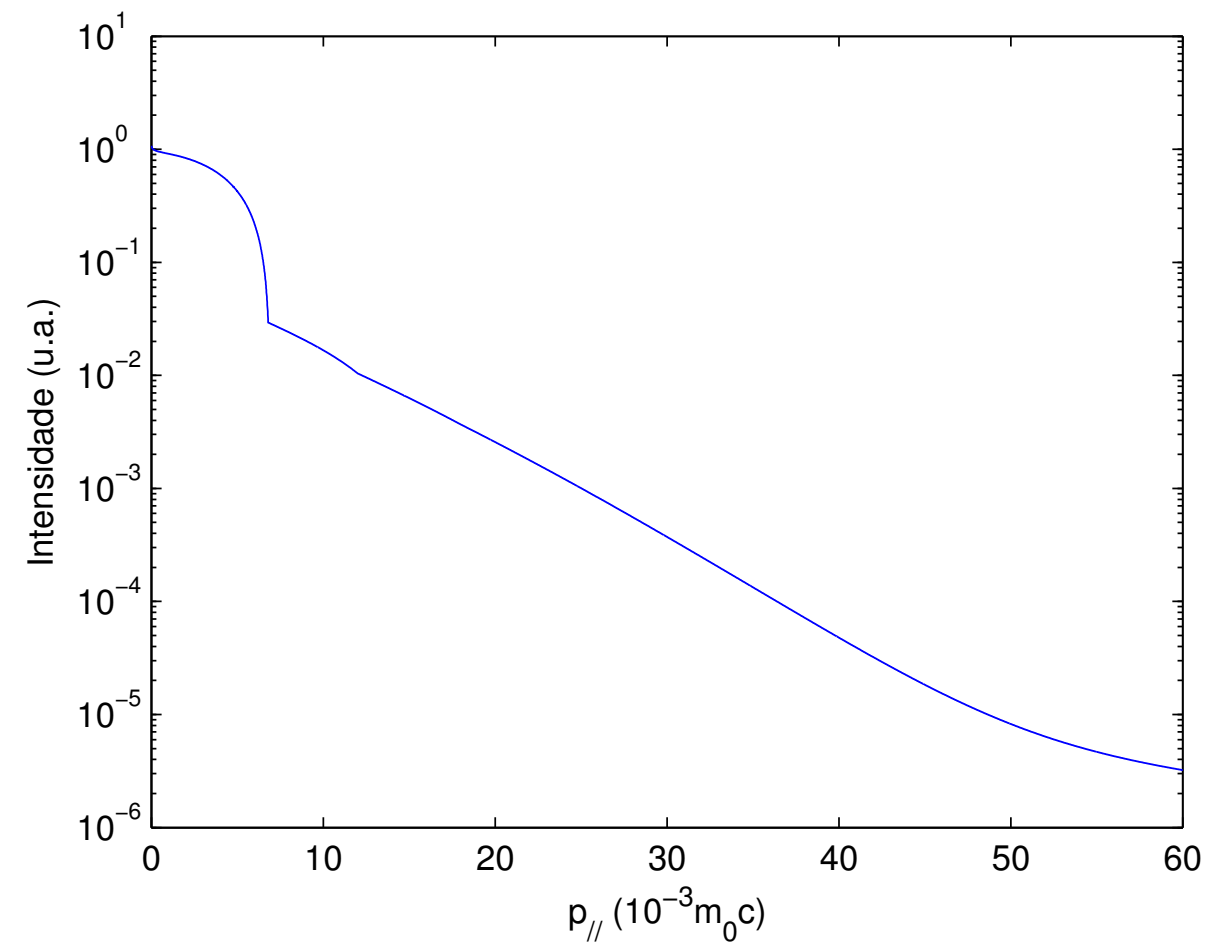

Figura 3.5: Espectro de alargamento Doppler $\left(f\left(p_{/ /}\right)\right)$calculada pelo modelo proposto, sem uso de filtro angular. 


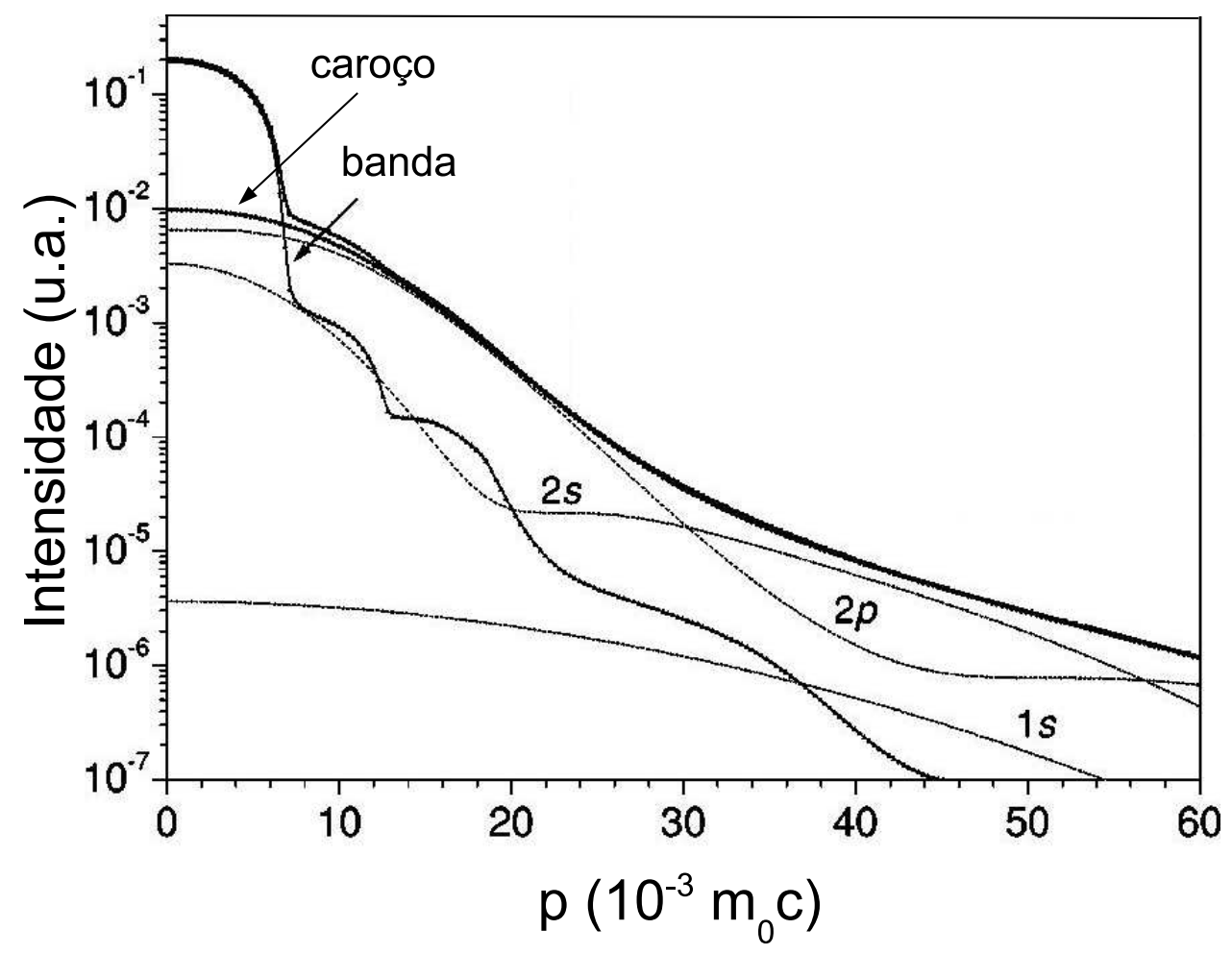

Figura 3.6: Espectro de alargamento Doppler calculado na referência [7]. 


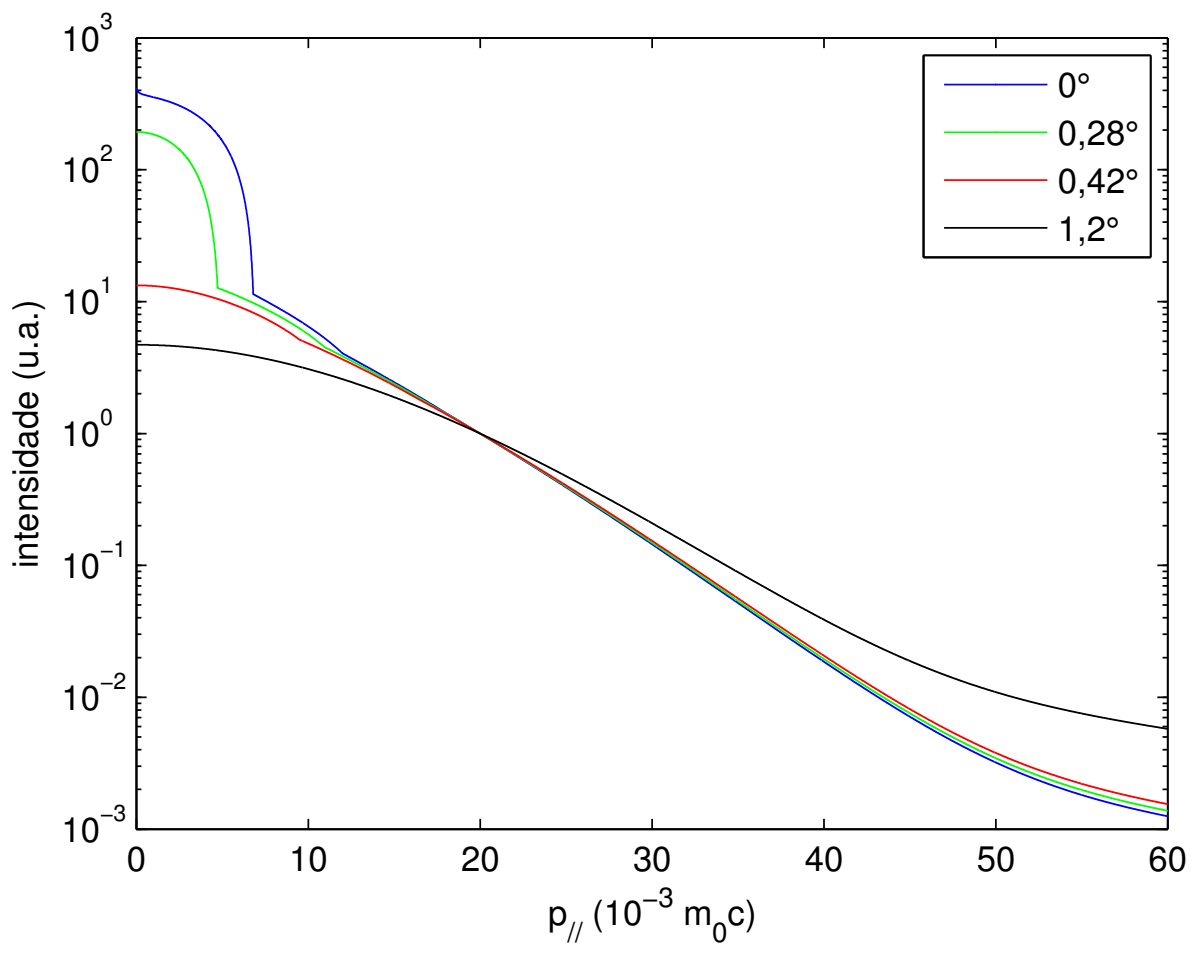

Figura 3.7: $f\left(p_{/ /}\right)$, para os ângulos utilizados neste experimento $\left(0^{\circ}, 0,28^{\circ}\right.$, $1,43^{\circ}$ e $\left.1,2^{\circ}\right)$. As curvas foram normalizadas arbitrariamente para coincidirem em $p_{/ /}=20 \cdot 10^{-3} m_{0} c$. É possível perceber que, quanto maior o ângulo de corte, menor a contribuição de aniquilações com elétrons de condução, que são excluídos devido a inserção do filtro angular.

$\left(0,42^{\circ}\right)$, não há mais aniquilações com elétrons de valência. Obviamente, como foi discutido na seção 2.2.1, a transmissibilidade do filtro deve ser convoluída com estes resultados, para se obter os espectros experimentais.

\subsubsection{Comparação com os valores medidos}

De posse da fdp de $p_{/ /}$é possível calcular $<p_{/ /}^{2}>$ através da equação 3.2 e assim estimar o $<\Delta E^{2}>$ para cada ângulo de corte através da equação 3.1 . Os resultados podem ser comparados com os experimentais apresentados no gráfico 3.4. Neste caso, deve-se incluir a transmissibilidade do filtro. Assim, a equação 3.2 pode ser escrita como: 


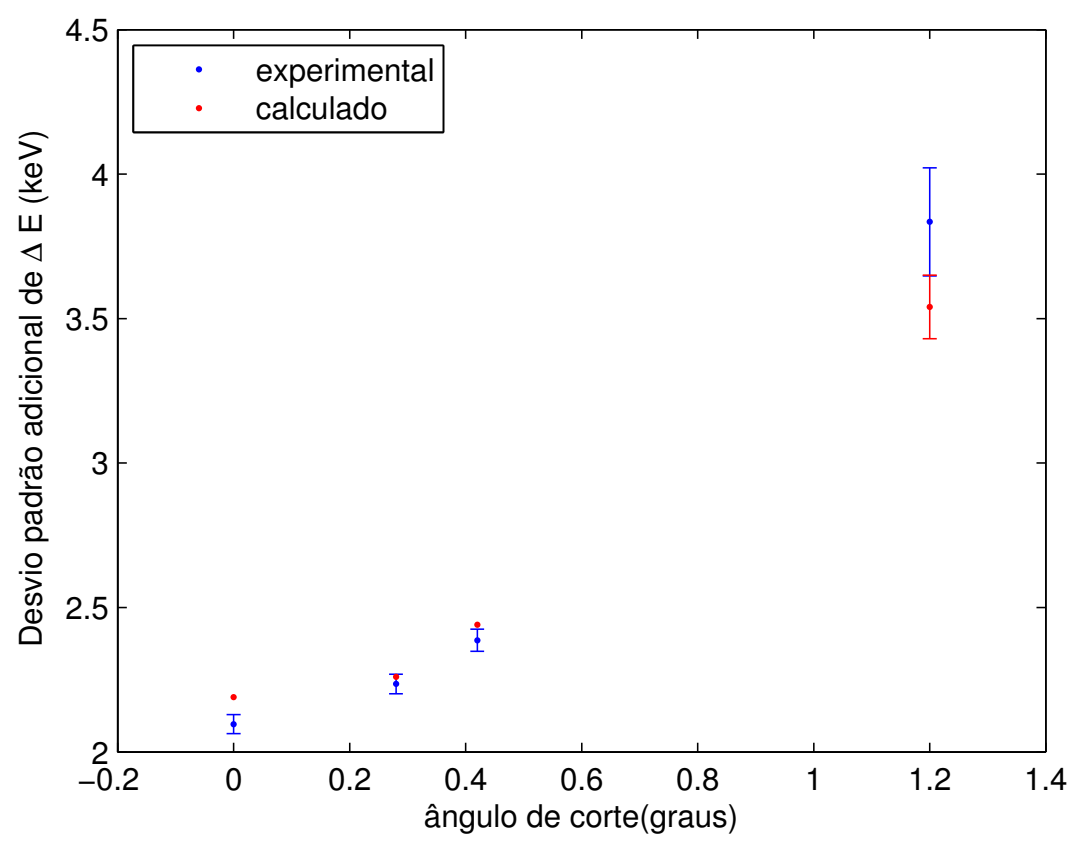

Figura 3.8: Largura adicional do espectro de $\Delta E$ em função do ângulo de corte e valores calculados pelo modelo descrito na seção 3.2 .

$$
<p_{/ /}^{2}>=\frac{\int_{-\infty}^{+\infty} \int_{p_{\perp_{c}}}^{+\infty} p_{/ /}^{2} g\left(p_{/ /}, p_{\perp}\right) T\left(p_{\perp}\right) d p_{\perp} d p_{/ /}}{\int_{-\infty}^{+\infty} \int_{p_{\perp_{c}}}^{+\infty} g\left(p_{/ /}, p_{\perp}\right) T\left(p_{\perp}\right) d p_{\perp} d p_{/ /}}
$$

sendo que $T(\alpha)$ foi avaliada na simulação descrita na seção 2.2.1 e $\alpha$ e $p_{\perp}$ se relacionam pela equação 1.4 .

A comparação entre os resultados obtidos pelo modelo descrito na seção 3.2 e os valores experimentais encontram-se na figura 3.8. Vale ressaltar que os valores calculados de $\sigma_{\text {adic }}$ contem incerteza, pois a transmissibilidade do filtro é calculada através de parâmetros experimentais. Nesta figura, é possível perceber que, o modelo desenvolvido, apesar de simples, apresenta ótima concordância com os resultados obtidos experimentalmente. 


\subsection{Ajuste}

A ideia inicial para a análise de dados era ajustar uma função modelo diretamente no espectro de coincidência, técnica desenvolvida em trabalhos realizados no próprio Laboratório do Acelerador Linear [4, 5, 13]. Porem, quando é usado o filtro angular a taxa de aniquilação é muito baixa e o número de contagens no pico de coincidência é relativamente pequeno (da ordem de milhares), de forma que em vários canais próximos ao pico de aniquilação não há nenhuma contagem (como pode ser visto na Figura 1.2).

A função de probabilidade do número de contagens no espectro de coincidência é Poisson. Quando o parâmetro dessa Poisson é muito pequeno (próximo de zero) o número de contagens observadas, muitas vezes é zero. Dessa forma, a incerteza deste canal, que é a raiz quadrada do parâmetro da Poisson, é muito difícil de ser estimada corretamente. Este fato dificulta o ajuste de uma função modelo diretamente no espectro de coincidência, usando o Método dos Mínimos Quadrados.

Algumas alternativas foram encontradas para contornar esse problema. A primeira delas foi ajustar as funções modelo nos espectros de diferença de energia, dados pela equação 1.5a. Um exemplo deste tipo de espectro é mostrado na figura 1.4. A segunda foi agrupar os espectros com ângulos semelhantes, criando apenas quatro grandes espectros com ângulo de corte de aproximadamente $0^{\circ}, 0,28^{\circ}, 0,42^{\circ}$ e $1,2^{\circ}$. A terceira foi utilizar o Método da Máxima Verossimilhança ao invés do Método dos Mínimos Quadrados para ajustar a função modelo aos dados experimentais, já que a incerteza dos dados não é conhecida [19].

A análise de dados sem o ajuste de funções modelo descrita na seção 3.2 mostra a eficácia do filtro angular. Porém, como em cada espectro de diferença de energia o número de eventos é muito baixo é necessário avaliar se o ajuste era sensível à inclusão de parâmetros relacionados à elétrons fortemente ligados.

As funções modelo escolhidas para o ajuste nos espectros de diferença de energia foram gaussianas centradas na origem. Esta escolha deve-se ao fato de que, mesmo para elétrons de condução, cuja $f d p$ de $p / /$ é parabó- 


\begin{tabular}{ccccc}
\hline ângulo & $\ln \left(\mathcal{L}_{A}\right)$ & $\ln \left(\mathcal{L}_{B}\right)$ & $\mathrm{D}$ & $P\left(\chi^{2}\right)$ \\
\hline $0^{\circ}$ & $-192,6$ & $-192,3$ & 0,6 & $74,1 \%$ \\
$0,28^{\circ}$ & $-207,6$ & $-204,9$ & 5,4 & $6,7 \%$ \\
$0,42^{\circ}$ & $-214,4$ & $-210,2$ & 8,4 & $1,4 \%$ \\
$1,2^{\circ}$ & $-88,2$ & $-83,0$ & 10,4 & $0,6 \%$ \\
\hline
\end{tabular}

Tabela 3.2: Comparação entre o ajuste de duas (modelo A) e três gaussianas (modelo B) aos espectros de diferença de energia. $P\left(\chi^{2}\right)$ é a probabilidade de se obter $\chi^{2} \geq D$ para 2 graus de liberdade

lica, quando esta é convolucionada com a função resposta do detector ela se torna muito semelhante a uma gaussiana. Visualmente, o ajuste de apenas uma gaussiana é inadequado para descrever o comportamento experimental. Assim, foram avaliados os ajustes de duas ou três gaussianas aos dados experimentais (equação 3.8).

$$
F(x)=\sum_{i=1}^{2 \text { ou3 }} \frac{N_{i}}{\sqrt{2 \pi} \sigma_{i}} \exp \left(-\frac{x^{2}}{2 \sigma_{i}^{2}}\right)
$$

Como a incerteza dos dados não é gaussiana e é desconhecida, devido ao problema da estimação do parâmetro da Poisson, quando o número de contagens observadas é zero, o teste de $\chi^{2}$ não pode ser utilizado para avaliar a qualidade do ajuste. Dessa forma, foram calculadas as funções verossimilhança $(\mathcal{L})$ para cada ajuste e foi feito o teste de razão de verossimilhança.

O teste de razão de Verossimilhança é utilizado para se comparar dois modelos $A$ e $B$ com $n_{A}$ e $n_{B}$ graus de liberdade, respectivamente. Pode-se demostrar [20] que a função densidade de probabilidade da razão

$$
D=-2 \ln \left(\frac{\mathcal{L}_{A}}{\mathcal{L}_{B}}\right)
$$

pode ser aproximada por uma distribuição de $\chi^{2} \operatorname{com}\left(n_{B}-n_{A}\right)$ graus de liberdade. A tabela 3.2 mostra os resultados obtidos para o ajuste de duas (modelo $\mathrm{A}, n_{A}=4$ ) e três gaussianas (modelo $\mathrm{B}, n_{B}=6$ ) centradas na origem.

A probabilidade de se obter $\chi^{2}$ maiores ou iguais a $D$ para dois graus de 




Figura 3.9: Espectro de $\Delta E$ e função ajustada para um espectro obtido sem o uso do filtro angular.

liberdade apresentados na tabela 3.2 mostra claramente que se devem ajustar três gaussianas aos espectros experimentais ao invés de duas, principalmente quando se analisam estes valores para os ângulos de corte maiores. As figuras 3.9, 3.10, 3.11 e 3.12 mostram os dados experimentais e as funções ajustadas para os ângulos de corte medidos. Os parâmetros ajustados encontram-se na tabela 3.3 . O valor ajustado para a terceira gaussiana tem incerteza assimétrica. Isto ocorre devido a função Verossimilhança não ser aproximadamente parabólica em torno de seu máximo [19].

A terceira gaussiana incluída no ajuste está relacionada a aniquilações com elétrons muito ligados e representa uma maneira análoga de avaliar a eficácia do filtro independente da modelagem feita na seção 3.2. A energia cinética do elétron, no caso de elétrons não relativísticos pode ser escrita como: 




Figura 3.10: Espectro de $\Delta E$ e função ajustada para um ângulo de corte de $0,28^{\circ}$.

\begin{tabular}{ccccccc}
\hline $\begin{array}{c}\text { ângulo } \\
\left({ }^{\circ}\right)\end{array}$ & $\begin{array}{c}A_{1} \\
(\text { cont. })\end{array}$ & $\begin{array}{c}\sigma_{1} \\
(\mathrm{keV})\end{array}$ & $\begin{array}{c}A_{2} \\
(\text { cont. })\end{array}$ & $\begin{array}{c}\sigma_{2} \\
(\mathrm{keV})\end{array}$ & $\begin{array}{c}A_{3} \\
(\text { cont. })\end{array}$ & $\begin{array}{c}\sigma_{3} \\
(\mathrm{keV})\end{array}$ \\
\hline 0 & $2129(27)$ & $1,902(21)$ & $167(16)$ & $4,50(18)$ & $8(5)$ & $7,1(18)$ \\
0,28 & $2022(29)$ & $1,898(22)$ & $325(23)$ & $3,60(13)$ & $58,9(10)$ & $6,5(4)$ \\
0,42 & $1515(26)$ & $1,898(30)$ & $456(25)$ & $3,20(10)$ & $68,0(10)$ & $6,7(4)$ \\
1,2 & $227(15)$ & $1,93(15)$ & $147(14)$ & $4,80(29)$ & $4,6(27)$ & $19_{-5}^{+54}$ \\
\hline
\end{tabular}

Tabela 3.3: Parâmetros da função 3.8 aos espectros diferença de energia. A notação $X_{-b}^{+a}$ indica que o intervalo de confiança correspondente a $68 \%$ é $[X-b, X+a]$, ou seja, não é simétrico 


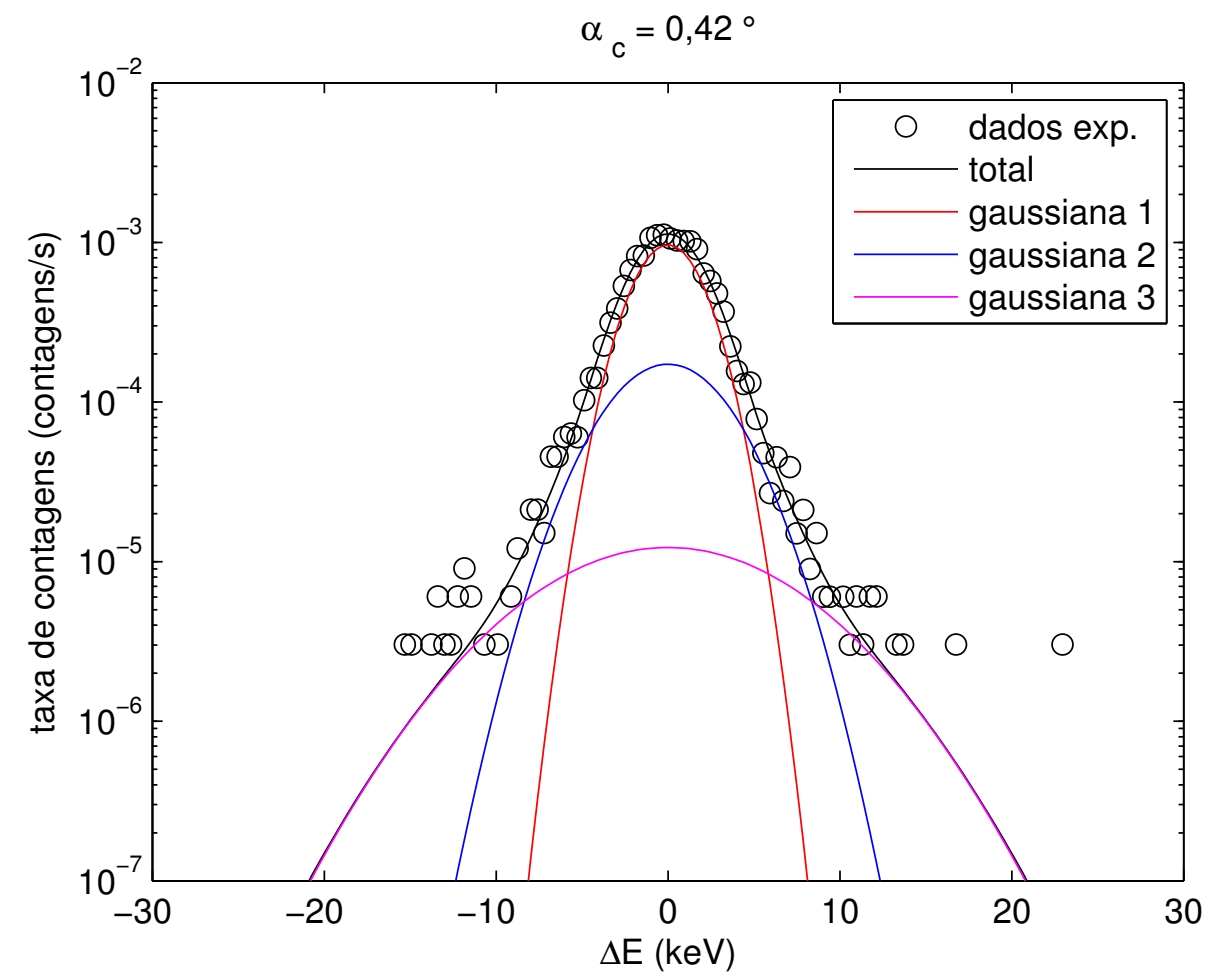

Figura 3.11: Espectro de $\Delta E$ e função ajustada para um ângulo de corte de $0,42^{\circ}$. 


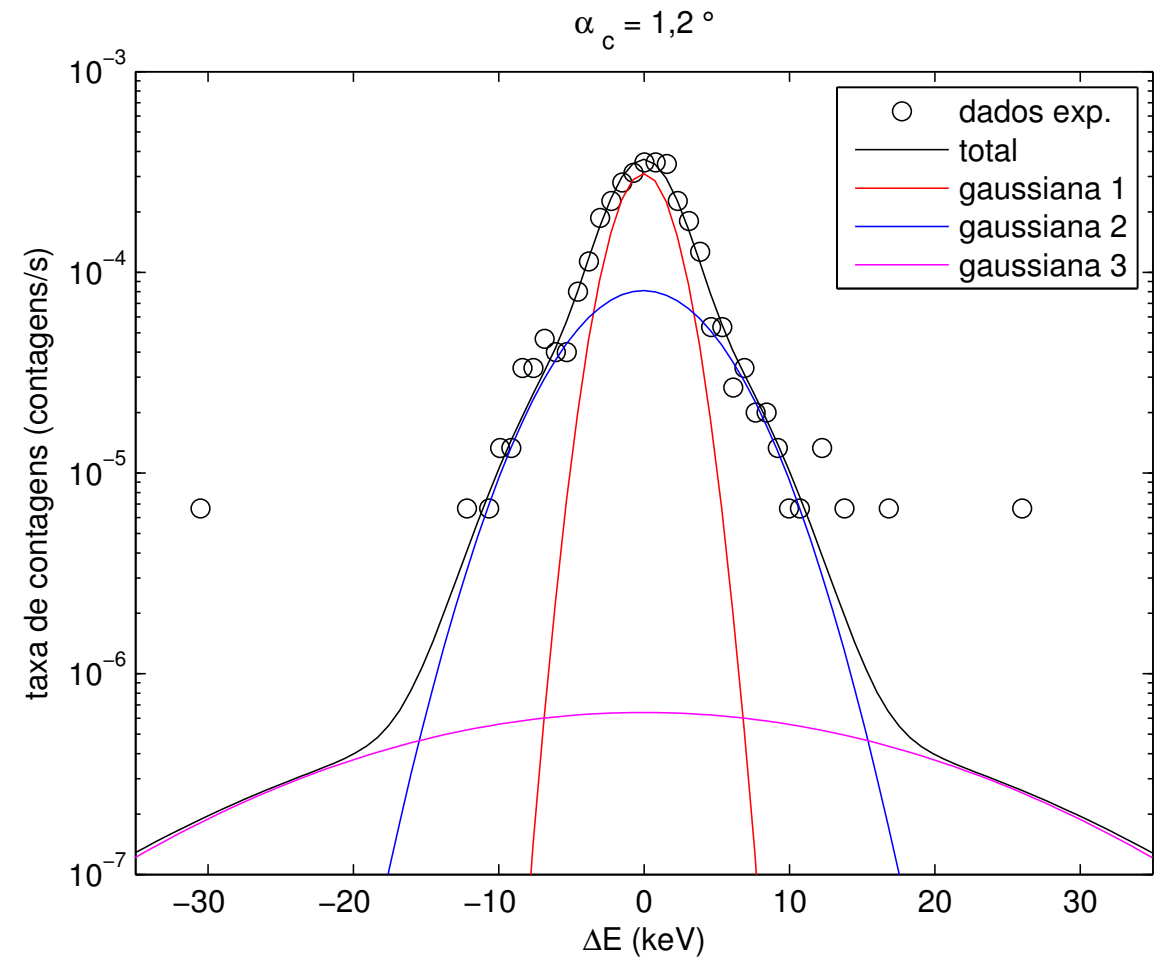

Figura 3.12: Espectro de $\Delta E$ e função ajustada para um ângulo de corte de $1,2^{\circ}$. 


\begin{tabular}{ccc}
\hline ângulo $\left(^{\circ}\right)$ & $\sigma_{3}(k e V)$ & $E_{c}^{\min }(k e V)$ \\
\hline 0 & $7,1(18)$ & $0,049(25)$ \\
0,28 & $6,5(4)$ & $0,041(5)$ \\
0,42 & $6,7(4)$ & $0,043(5)$ \\
1,2 & $19_{-5}^{+54}$ & $0,35_{-0,19}^{+2,0}$ \\
\hline
\end{tabular}

Tabela 3.4: Energia cinética mínima do elétron.

$$
E_{c}=\frac{p^{2}}{2 m}=\frac{p_{/ /}^{2}+p_{\perp}^{2}}{2 m}
$$

Assim,

$$
E_{c} \geq \frac{p_{/ /}^{2}}{2 m}
$$

substituindo a equação 3.1

$$
E_{c} \geq \frac{\Delta E^{2}}{2 m c^{2}}
$$

Dessa forma, utilizando-se a largura ajustada para a terceira gaussiana pode-se calcular a energia cinética mínima dos elétrons. Os valores calculados encontram-se na tabela 3.4 .

Os resultados obtidos indicam claramente a efetividade do filtro angular. A necessidade do ajuste da terceira gaussiana é evidente e cresce a medida que o ângulo de corte aumenta como mostra o teste estatístico da hipótese de que a melhora da verossimilhança tenha sido fruto de mero acaso (tabela 3.2). Além disso, quando o ângulo de corte é $1,2^{\circ}$, a energia cinética mínima calculada é compatível com energias de ligação com elétrons $2 s$, cuja energia de ligação é de $0,12 \mathrm{keV}$ ou, ainda, com elétrons mais ligados. Este fato, fica ainda mais evidente quando se calcula a energia cinética mínima para alguns eventos com $\Delta E \approx 30 \mathrm{keV}$ (figura 3.12). Nesse caso, $E_{c}^{\text {mín }} \approx 1 \mathrm{keV}$, cuja origem só pode ser aniquilações com elétrons $1 \mathrm{~s}$. 


\section{Capítulo 4}

\section{Conclusão e perspectivas}

Neste trabalho, foi desenvolvido um filtro angular que permite selecionar aniquilações com elétrons fortemente ligados em experimentos de aniquilação de pósitrons. Este filtro reduz, significativamente, contribuições de aniquilações com elétrons de valência, permitindo caracterizar o elemento químico do material no qual ocorreu a aniquilação, através de sua energia de ligação.

Foram medidos espectros de coincidência no alumínio com o uso deste filtro angular. A redução das aniquilações com elétrons de valência pode ser vista diretamente no espectros de diferença de energia mostrados nas figuras 3.2 e 3.3 .

As principais técnicas para o estudo de aniquilações com elétrons fortemente ligados, principalmente da camada $1 \mathrm{~s}$, dependiam de uma modelagem detalhada do espectro de coincidência ou da medida dos fótons provenientes da aniquilação em coincidência com elétrons Auger. O filtro angular, desenvolvido neste trabalho se coloca como alternativa promissora a estes métodos.

Devido ao fato da amostra não ser puntiforme e de existirem incertezas no tamanho e posicionamento das peças que compunham o filtro angular, a transmissibilidade do filtro é uma função suave do ângulo entre os gamas. Esta função foi avaliada através de uma simulação pelo método de Monte Carlo. Um exemplo de resultado desta simulação encontra-se na figura 2.4 . Os resultados mostraram que a incerteza no tamanho da amostra é funda- 
mental para a incerteza no ângulo de corte. Este fator deve ser levado em conta em experimentos futuros e a forma da amostra deve ser otimizada. Reduzir a incerteza no ângulo de corte intensificará muito os efeitos observados.

Foi feito também um estudo e modelagem simples das funções densidade de probabilidade de $p / /$. Apesar de simples, esta modelagem apresentou resultados muito semelhantes aos obtidos na literatura e suficientemente precisos para interpretação teórica dos resultados obtidos. Esta modelagem permitiu, também, entender melhor o funcionamento do filtro angular e calcular os valores esperados da dispersão da diferença de energia. Os valores calculados apresentaram um ótimo acordo com os dados experimentais, como mostra a figura 3.8. O ajuste de funções modelo aos espectros de coincidência também permitiram avaliar a eficácia do filtro.

Uma perspectiva interessante deste trabalho é, com um conjunto maior de dados experimentais do que o obtido neste trabalho, ajustar as $f d p$ de $p_{/ /}$, convolucionadas com a função resposta dos detectores e com a transmissibilidade do filtro angular, diretamente aos espectros de diferença de energia. Nesse caso, poderia se obter, diretamente, os momentos de Fermi e energias de ligação dos elétrons como parâmetros do ajuste. 


\section{Referências Bibliográficas}

[1] BERINGER, R.; MONTGOMERY, C. G. The angular distribution of positron annihilation radiation. Physical Review, American Physical Society, v. 61, n. 5-6, p. 222-224, Mar 1942.

[2] DEBENEDETTI, S. et al. On the angular distribution of two-photon annihilation radiation. Physical Review, American Physical Society, v. 77, n. 2, p. 205-212, Jan 1950.

[3] LYNN, K. G. et al. Positron-annihilation momentum profiles in aluminum: Core contribution and the independent-particle model. Physical Review Letters, American Physical Society, v. 38, n. 5, p. 241-244, Jan 1977.

[4] NASCIMENTO, E. do et al. Doppler broadening of positron annihilation radiation: fitting the coincidence spectrum. Nuclear Instruments 85 Methods in Physics Research A, v. 538, n. 1-3, p. 723 - 730, 2005. ISSN 0168-9002.

[5] NASCIMENTO, E. do et al. Statistical analysis of the doppler broadening coincidence spectrum of electron-positron annihilation radiation in silicon. Nuclear Instruments 8 Methods in Physics Research A, v. 609, p. $244-$ 249, 2009. ISSN 0168-9002.

[6] KRAUSE-REHBERG, R.; LEIPNER, H. Positron Annihilation in Semiconductors. Berlin: Springer-Verlag, 1999. (Springer series in Solid States Sciences).

[7] TANG, Z. et al. First-principles calculation of coincidence doppler broadening of positron annihilation radiation. Physical Review B, 2002.

[8] KIM, S. et al. Gamma-ray spectra resulting from the annihilation of positrons with selected core levels of $\mathrm{Cu}, \mathrm{Ag}$, and Au. Physical Review B, v. 73, n. 014114 , p. 7 , Jan 2006.

[9] FERRELL, R. Theory of positron annihilation in solids. Reviews of Modern Physics, American Physical Society, v. 28, n. 3, p. 308-337, 1956. 
[10] JACKSON, J. D. Classical Electrodynamics. 3. ed. New York: John Wiley and Sons, 1998.

[11] National Institute of Standards and Technology - NIST. Stopping-Power and Range Tables for Electrons, Protons, and Helium Ions. 2010. Online; acessada em 16 de Setembro de 2010. Disponível em: <http://www.nist. gov/physlab/data/star/index.cfm>.

[12] MIJNARENDS, P. et al. Two-detector doppler broadening study of enhancement in Al. Journal of Physics: Condensed Matter, v. 10, n. 46, p. 10383 - 10390, 1998. ISSN 0953-8984.

[13] NASCIMENTO, E. do et al. Statistical analysis of the doppler broadening coincidence spectrum of the electron-positron annihilation radiation in aluminum. Nuclear Instruments 8 Methods in Physics Research B, v. 247 , n. 1 , p. 38 - 41, 2006. ISSN 0168-583X.

[14] FIRESTONE, R. B. Table of Isotopes. 8. ed. New York: John Wiley and Sons, 1996.

[15] KNOLL, G. F. Radiation Detection and Measurement. [S.l.]: John Wiley \& Sons, 1979.

[16] VANIN, V. R. et al. XIX Reunião de Trabalho sobre Física Nuclear no Brasil. In: Caderno de Resumos. Águas de Lindóia, SP: Sociedade Brasileira de Física, 1996.

[17] TSAI, S. P.; MUCCIOLO, E. R.; HELENE, . Relocation of multichannel spectra. Nuclear Instruments \& Methods in Physics Research A, 1994.

[18] GHOSH, V. et al. Calculation of the doppler broadening of the electronpositron annihilation radiation in defect-free bulk materials. Physical Review $B$, v. 61, n. 15, p. 10092 - 10099, 2000. ISSN 0163-1829.

[19] VAnin, V. R.; GOUfFOn, P.; HELENE, O. Análise Estatistica de Medidas em Ciências Exatas. São Paulo: LAL-IFUSP, 2005.

[20] KEnDALL, M. G.; STUART, A. The Advanced Theory of Statistics. 4. ed. London: Griffin, 1979. 